LBNL-48334

\title{
Effects of Composition and Exposure On the Solar Reflectance Of Portland Cement Concrete
}

\author{
Ronnen Levinson and Hashem Akbari \\ Heat Island Group \\ Environmental Energy Technologies Division \\ Lawrence Berkeley National Laboratory \\ University of California \\ Berkeley, CA 94720
}

December 2001

This work was supported by the Assistant Secretary for Energy Efficiency and Renewable Energy, Building Technologies, of the U.S. Department of Energy (DOE) under contract No. DE-AC03-76SF00098, and by the U.S. Environmental Protection Agency (EPA) under IAG No. DW89938351-01. 



\title{
Effects of Composition and Exposure On the Solar Reflectance Of Portland Cement Concrete
}

\author{
Ronnen Levinson and Hashem Akbari \\ Heat Island Group \\ Environmental Energy Technologies Division \\ Lawrence Berkeley National Laboratory \\ University of California \\ Berkeley, CA 94720
}

\begin{abstract}
Increasing the solar reflectance (albedo) of a paved surface keeps it cooler in the sun, reducing convection of heat from pavement to air and thereby decreasing the ambient air temperature. Simulations of the influence of pavement albedo on air temperature in Los Angeles predict that increasing the albedo of $1,250 \mathrm{~km}^{2}$ of pavement by 0.25 would save cooling energy worth $\$ 15 \mathrm{M} \mathrm{yr}^{-1}$, and reduce smog-related medical and lost-work expenses by $\$ 76 \mathrm{M} \mathrm{yr} \mathrm{r}^{-1}$. Most sidewalks and a small fraction of roads and parking areas are paved with portland cement concrete, which can be made quite reflective through suitable choice of cement and aggregate. Variations with composition and environmental exposure of the albedos of portland cement concrete pavements were investigated through laboratory fabrication and exposure of 32 mixes of concrete.
\end{abstract}

Twenty-four mixes yielded substandard, "rough" concretes due to high, unmet aggregate water demand. The albedos of the remaining eight "smooth" concrete mixes ranged from 0.41 to 0.77 (mean 0.59). Simulated weathering, soiling, and abrasion each reduced average concrete albedo (mean decreases $0.06,0.05$, and 0.19 , respectively), though some samples became slightly more reflective through weathering or soiling. Simulated rain (wetting) strongly depressed the albedos of concretes (mean decrease 0.23) until their surfaces were dried. Concrete albedo grew as the cement hydration reaction progressed (mean increase 0.08 ), but stabilized within six weeks of casting.

White-cement concretes were on average significantly more reflective than gray-cement concretes. The albedo of the most-reflective white-cement concrete was 0.18 to 0.39 higher than that of the most-reflective gray-cement concrete, depending on state of exposure. Concrete albedo generally correlated with cement albedo and sand albedo, and, after abrasion, with rock albedo. Cement albedo had a disproportionately strong influence on the reflectance of concrete. Efflorescence and surface carbonation whitened some gray-cement mixes. 



\section{Acknowledgements}

This work was supported by the Assistant Secretary for Energy Efficiency and Renewable Energy, Building Technologies, of the U.S. Department of Energy (DOE) under contract No. DE-AC0376SF00098, and by the U.S. Environmental Protection Agency (EPA) under IAG No. DW89938351-01. We acknowledge the support and guidance of Jeanne Briskin, Edgar Mercado, and Eva Wong of the EPA.

We also thank those who provided us with facilities, analysis, and feedback, including Prof. Paulo Monteiro, Prof. Carl L. Monismith, and Lev Stepanov, Department of Civil and Environmental Engineering, University of California at Berkeley; Dr. Melvin Pomerantz and Dr. Paul Berdahl, Environmental Energy Technologies Division, Lawrence Berkeley National Laboratory; Dr. Mack Kennedy, Dr. Marshall Parker, and Dr. Matthijs van Soest, Earth Sciences Division, Lawrence Berkeley National Laboratory; Matt McPharlin, the Granite Company; and Martha VanGeem, Construction Technology Laboratories. 



\section{Table of Contents}

Abstract
Acknowledgements
Table of Contents
$\mathbf{1}$
$\mathbf{2}$
$\mathbf{2}$
$\mathbf{2}$

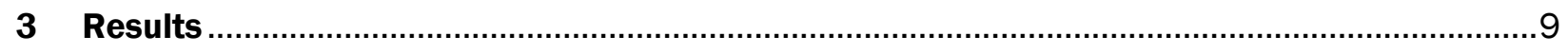

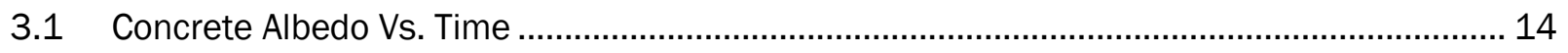

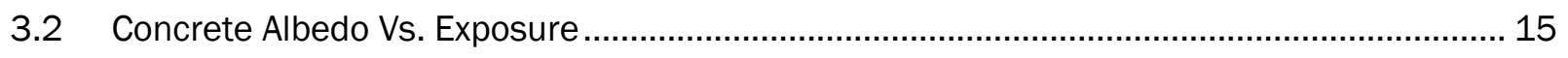

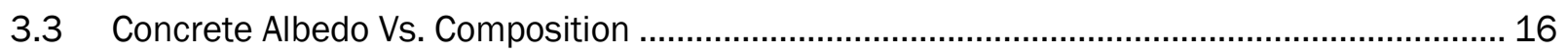

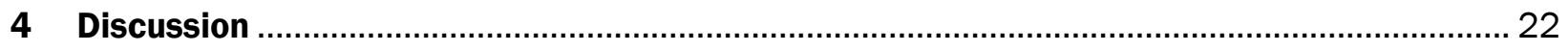

4.1 Reflectance as an Indicator of Cement and Concrete Chemistry ...................................... 22

4.2 Making High-Albedo Concrete: White Cement Vs. Gray Cement ......................................... 23

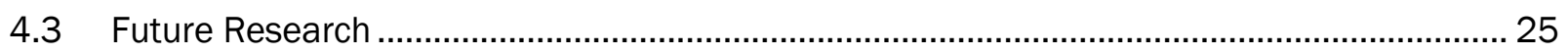

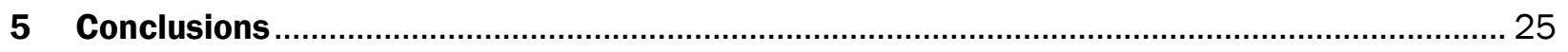

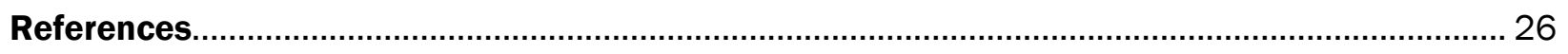

Appendix A: Effects of Wetting and Drying on Rate of Concrete Albedo Growth ....................... 29

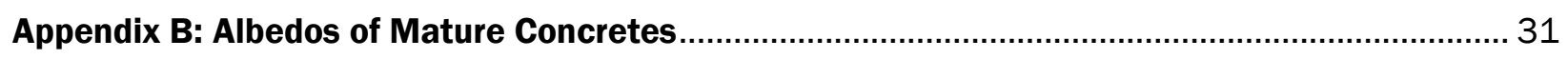





\section{List of Figures}

Figure 1. Properties of concrete components........................................................................

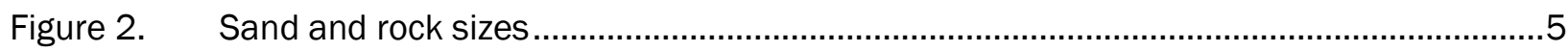

Figure 3. Surfaces of concrete sample quarter-disk .............................................................. 6

Figure 4. Properties of mature, unexposed concretes ................................................................... 7

Figure 5. Properties of all mature concretes.............................................................................. 10

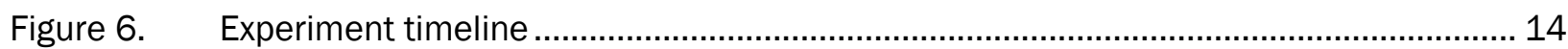

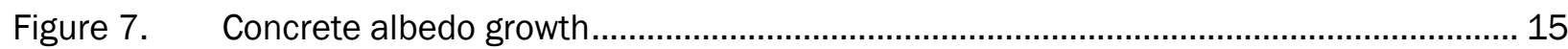

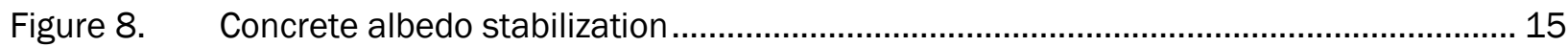

Figure 9. Albedos of immature, unexposed concretes........................................................... 17

Figure 10. Albedos of mature, unexposed concretes ............................................................. 18

Figure 11. Mature concrete albedo vs. exposure ...................................................................... 19

Figure 12. Mature, smooth concrete albedo vs. composition....................................................... 21

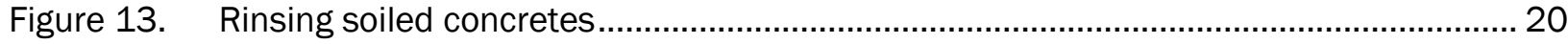

Figure 14. Measured and predicted mature albedos of the most-reflective white-cement and gray-cement smooth concretes ....................................................... 24

Figure A-1. Set-to-set differences in albedos of unexposed concretes .......................................... 30

Figure A-2. Immediate effect of drying on albedo of wet concrete .................................................. 30

Figure A-3. Effect of wetting and drying on albedo growth in immature concretes .........................30

Figure A-4. Effect of wetting and drying on albedo growth in mature concretes ............................30

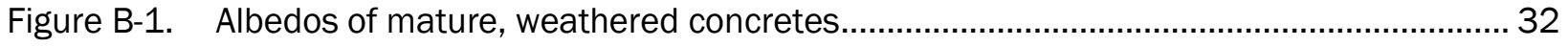

Figure B-2. Albedos of mature, wet, weathered concretes........................................................ 33

Figure B-3. Albedos of mature, soiled concretes .................................................................... 34

Figure B-4. Albedos of mature, abraded concretes .................................................................... 35

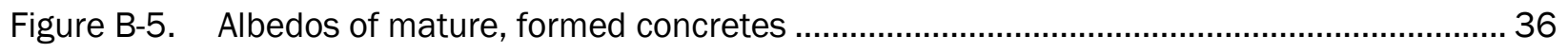

Figure B-6. Mature, smooth concrete albedo vs. cement albedo .................................................. 37

Figure B-7. Mature, smooth concrete albedo vs. sand albedo ..................................................... 38

Figure B-8. Mature, smooth concrete albedo vs. rock albedo ....................................................... 39 



\section{List of Tables}

Table 1. Concrete-pavement land coverage in two cities ..........................................................1

Table 2. Colors of some iron-oxide minerals...............................................................................

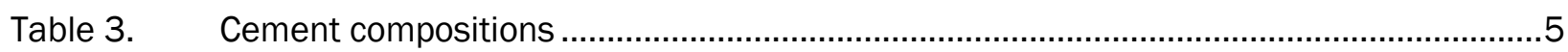

Table 4. Correlation of smooth-concrete albedo to component albedo ...................................... 20

Table 5. Combining exposure-induced albedo changes ............................................................ 23 



\section{Introduction}

Increasing the solar reflectance ("albedo") of a paved surface keeps it cooler in the sun, reducing convection of heat from pavement to air and thereby decreasing the ambient air temperature. Lower air temperatures decrease demand for cooling energy and slow the formation of urban smog. Simulations of the influence of pavement albedo on air temperature in Los Angeles predict that increasing the albedo of $1,250 \mathrm{~km}^{2}$ of pavement by 0.25 would save cooling energy worth $\$ 15 \mathrm{M} \mathrm{rr}^{-1}$, and reduce smog-related medical and lost-work expenses by $\$ 76 \mathrm{M} \mathrm{yr} \mathrm{r}^{-1}$ (Rosenfeld et al. 1998).

Most sidewalks and a small fraction of roads and parking areas are paved with portland cement concrete (hereafter, simply “concrete"). Concrete can be made quite reflective through suitable choice of cement and aggregate. Photographic land-cover analyses indicate that pavement covers $41 \%$ of the surface of the developed regions of Sacramento, CA (Akbari et al. 1999) and 31\% of the surface of the developed regions of Salt Lake City, UT (Akbari and Rose 2001). Assuming that 95\% of sidewalks and $5 \%$ of roads and parking areas are paved with concrete, concrete covers about 16 to $20 \%$ of the paved surface area and 6 to $7 \%$ of the total surface area in these two cities (Table 1).

Concrete is formed by curing a mixture of cement, water, fine aggregate (sand) and coarse aggregate (stone or crushed rock). Its composition and hence its appearance depend on the progress of the cement hydration reaction, the rate and products of which are well known (Brunauer and Copeland 1964; Papadakis and Vayenas 1991). Color can be imparted by using naturally colored cements, by adding pigments (primarily iron oxides) to the mixture or surface, or by exposing colored aggregate (Lea 1998; Hurd 1993; Kirk-Othmer 1979; Nasvik 2000; Schierhorn 1996; Hurd 1988). Concrete surfaces can be "frosted"-that is, coated with a white film-through efflorescence (the leaching of salts, particularly calcium hydroxide, from interior to surface) and carbonation (the reaction of calcium hydroxide with atmospheric carbon dioxide to form calcium carbonate) (Kenney 1996; Hooker 1994; Newman 2000). Soiling, wetting, growth of lichen and moss, and reactions with certain aggregates (e.g., iron pyrites) are also known to change the appearance of concrete (Goode 1991).

The visible reflectance of pavement is of interest to transportation engineers concerned with lane marking and artificial illumination of roads (CIE/PIARC 1977; Homburger and Kell 1984; IES 1983); some measurements are available (Jung et al. 1984; Jackett and Fisher 1974). However, a surface's

Table 1. Concrete-pavement land coverage in two cities. Shown are pavement coverage of Sacramento, CA and Salt Lake City, UT, and the fractions of paved surface areas and total surface areas covered with concrete. It is assumed that $95 \%$ of sidewalks and $5 \%$ of roads and parking areas are concrete.

\begin{tabular}{c|cccc|cc} 
& \multicolumn{4}{|c|}{ Land Cover Fraction } & \multicolumn{2}{c}{ Coverage By Concrete } \\
\hline & & & Parking & All & Paved & All \\
City & Roads & Sidewalks & Areas & Pavements & Surfaces & Surfaces \\
Sacramento, CA & $24 \%$ & $5 \%$ & $12 \%$ & $41 \%$ & $16 \%$ & $7 \%$ \\
Salt Lake City, UT & $15 \%$ & $5 \%$ & $11 \%$ & $31 \%$ & $20 \%$ & $6 \%$
\end{tabular}


solar reflectance can differ from its visible reflectance because visible light (wavelengths 400-700 $\mathrm{nm}$ ) accounts for only $43 \%$ of the energy in the solar spectrum (300-2,500 nm). Another $52 \%$ lies in the near-infrared (700-2,500 nm), and 5\% in the ultraviolet (300-400 nm) (ASTM 1998). No studies of the influences of composition and/or exposure on the solar reflectance of concrete were found in an extensive electronic search of engineering, physics, material science, and transportation literatures.

There are no standard tests for the variation of the solar reflectance of pavement with weathering, wetting, abrasion, or soiling, though ASTM Practice G154-00ae1 ("standard practice for operating fluorescent light apparatus for UV exposure of nonmetallic materials”) provides test cycles that simulate weathering by moisture and direct sunlight (ASTM 2001), and ASTM Practice E660-90 (1996) ("standard practice for accelerated polishing of aggregates or pavement surfaces using a smallwheel, circular track polishing machine") specifies a procedure for the accelerated polishing of pavement (ASTM 1999).

In this study, the variation with composition and environmental exposure of the solar reflectance of portland cement concrete pavement is investigated through laboratory fabrication and exposure of 32 mixes of concrete. The terms albedo and reflectance will be used interchangeably to denote solar reflectance.

\section{Experiment}

Concrete cylinders were cast from a variety of cements, sands, and rocks, and then exposed to simulated weathering, soiling, abrasion, and rain. Their albedos were measured before and after exposure over a 69-week period, and compared to those of their constituents.

\subsection{Albedo Measurements}

Five (or in the case of cut concrete surfaces, 10) readings of a solar-spectrum reflectometer (Devices \& Services model SSR-ER; 300-2,500 nm) were averaged to measure air-mass 1.5 albedos ${ }^{1}$ of cements, sands, rocks, and concretes. Since wetting markedly changes the reflectance of most surfaces (Twomey et al. 1986), aggregates and concretes not intentionally wetted were driedaggregates on a hot plate, and concretes with a hot-air gun-prior to albedo measurement.

The rocks were too small to fill the 25-mm-diameter aperture of the reflectometer, and too irregularly shaped to combine to form a larger flat surface. To determine their albedos, measurements were

\footnotetext{
1 The air-mass 1.5 albedo of a surface refers to its ability to reflect sunlight that has a spectral irradiance distribution characteristic of having traversed an atmospheric path length equal to 1.5 times the height of the earth's atmosphere. This path length corresponds to a solar altitude of $42^{\circ}$. An air-mass 1.5 irradiance is representative of average conditions in the contiguous United States (ASTM 1998).
} 
made with the aperture covered by a black disk with an 8-mm-diameter hole. The albedo of each rock, $\rho_{r}$, was calculated from

$$
\rho_{r}=\rho_{b}+\left(\rho_{w}-\rho_{b}\right) \times \frac{\rho_{r}^{\prime}-\rho_{b}^{\prime}}{\rho_{w}^{\prime}-\rho_{b}^{\prime}}
$$

where $\rho_{w}^{\prime}, \rho_{b}^{\prime}$, and $\rho_{r}^{\prime}$ were the reflectances measured through the disk of a white standard, a black standard, and the rock face, respectively; and $\rho_{w}$ and $\rho_{b}$ were the albedos of the white and black standards, respectively.

Some concretes had rough surfaces that allowed light to escape from the reflectometer-surface interface, yielding erroneously low measurements. The magnitude of this error is unknown.

\subsection{Cement, Sand, and Rock Properties}

Thirty-two mixes of concrete were cast from two types of cement (C1, C2: albedo $\rho=0.32,0.87$ ); four types of sand (S1...S4: $\rho=0.20,0.22,0.27,0.45$ ); and four types of rock (R1...R4: $\rho=0.17,0.19$, $0.49,0.55)$ (Figure 1). Components were chosen for their varied colors and reflectances, and are numbered in order of increasing albedo.

One of the sands (S2, basalt) is naturally dark red in

Table 2. Colors of some iron-oxide minerals. color. The other three sands (S1, a dark gray riverbed sand; S3, a brown sand; and S4, a tan beach sand) were observed to contain primarily transparent or white materials: quartz, clay minerals, and, in the cases of S1 and S4, mica. This suggests that these sands contain other mineral colorants. Red, brown, and black iron-oxide impurities (Table 2) are common because oxygen (0) and

\begin{tabular}{c|c|c} 
name & formula & color \\
\hline hematite & $\mathrm{Fe}_{2} \mathrm{O}_{3}$ & red-brown to black \\
\hline magnetite & $\mathrm{Fe}_{3} \mathrm{O}_{4}$ & black or red-black \\
\hline goethite & $\mathrm{FeO}(\mathrm{OH})$ & brown or blackish \\
\hline wuestite & $\mathrm{FeO}$ & black
\end{tabular}
iron (Fe) constitute about $46 \%$ and $6 \%$, respectively, of the mass of the Earth's crust (Lide 1990). For example, the white cement (C2) appears lighter than the gray cement (C1) because it contains less hematite, an iron oxide (Table 3). The four rocks (R1, dark red basalt; R2, black and red granite; R3, white plagioclase; and R4, gold and white chert with iron impurities) were dusty.

Sand particle size distributions were measured with a six-sieve cascade [U.S. standard mesh numbers 14 (1.41 mm), 18 (1.00 mm), $20(0.850 \mathrm{~mm}), 35(0.500 \mathrm{~mm}), 60(0.250 \mathrm{~mm})$, and $230(0.063$ $\mathrm{mm})$ ]. Rock size distributions were determined by measuring the mass $m_{i}$ of each of 10 randomly selected samples, and measuring the volume of water $V$ displaced by all 10 samples. The diameter of each sample, $d_{i}$, was approximated by

$$
d_{i}=\left(m_{i} V / M\right)^{1 / 3}
$$

where $M$ is the total mass of the 10 samples. Sand mass-mean diameters ranged from 0.40 to $0.98 \mathrm{~mm}$, while rock mass-mean diameters ranged from 14 to $18 \mathrm{~mm}$ (Figure 2). 


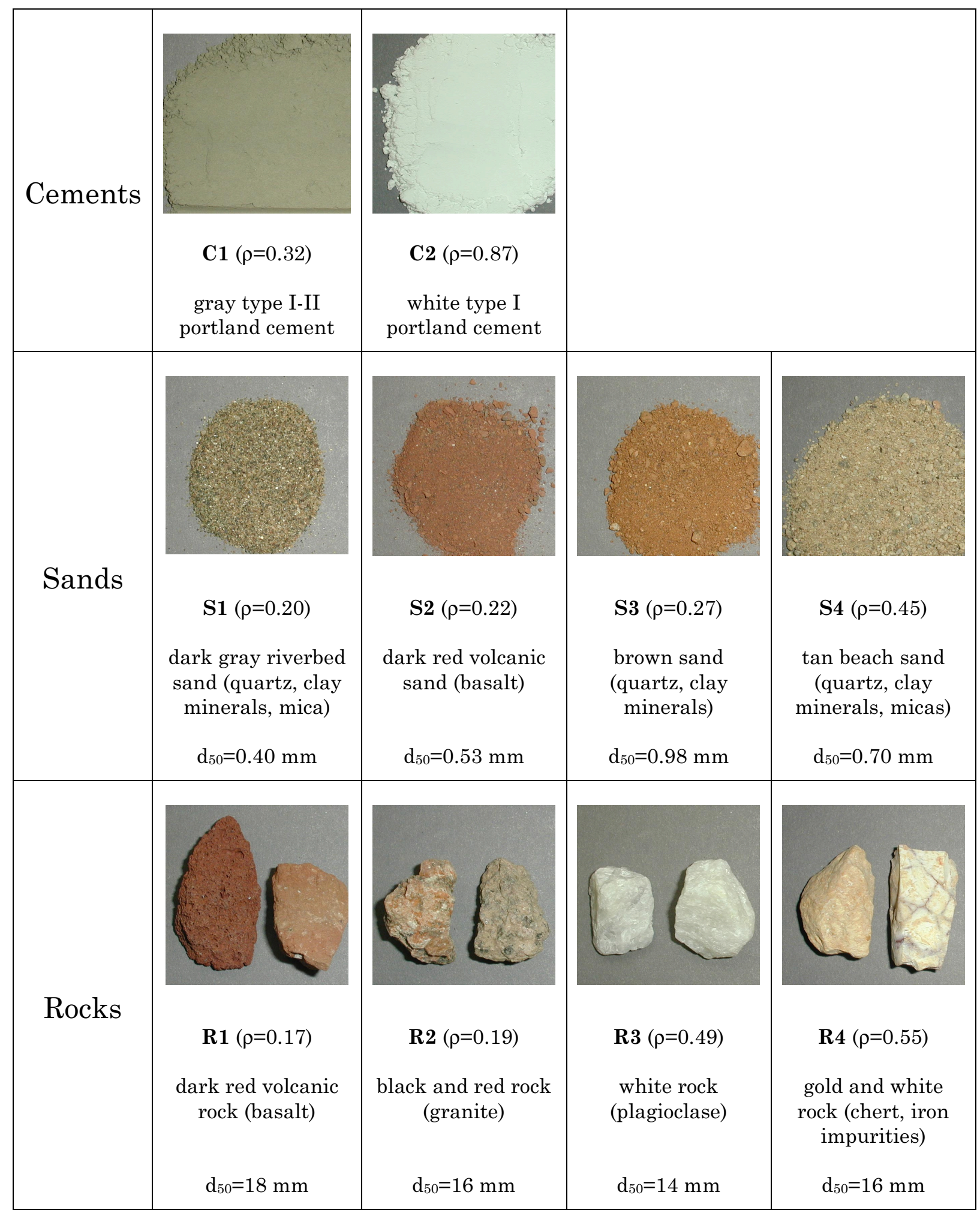

Figure 1. Properties of concrete components. Shown are the albedo $\rho$, mass-mean diameter $d_{50}$, composition and image of each of the two cements, four sands, and four rocks used to form 32 mixes of concrete. 
Table 3. Cement compositions. Shown are manufacturer-reported chemical mass fractions of the gray and white cements. The gray cement is colored primarily by hematite $\left(\mathrm{Fe}_{2} \mathrm{O}_{3}\right)$.

\begin{tabular}{c|c|c|c|c|c|c} 
Cement & $\mathbf{S i O}_{\mathbf{2}}(\%)$ & $\mathbf{A l}_{\mathbf{2}} \mathbf{O}_{\mathbf{3}}$ (\%) & $\mathbf{F e}_{\mathbf{2}} \mathbf{O}_{\mathbf{3}}$ (\%) & $\mathbf{C a O}(\%)$ & $\mathbf{M g 0}(\%)$ & $\mathbf{S O}_{\mathbf{3}}(\%)$ \\
\hline gray type I-II (C1) & 21.9 & 4.3 & 3.5 & 63.6 & 1.9 & 2.5 \\
\hline white type I (C2) & 22.7 & 5.1 & 0.2 & 67.5 & 0.8 & 2.7
\end{tabular}

\subsection{Concrete Fabrication}

Cement, sand, rock, and water were hand mixed in medium-strength-concrete mass proportions of 1/2.3/2.8/0.6 (Mehta 1993), and poured into 100-mm-high, 100-mm-diameter cylindrical plastic molds. The wet concrete was rodded, vibrated, and troweled to uniformly distribute aggregate, remove air bubbles, and level the "finished" upper surface. The molds were sealed at time $t=0$ and their contents hardened overnight, after which the concrete cylinders were removed from their molds to cure for five days in a saturated-air environment.

A 25-mm-thick disk was sliced from the top of each concrete cylinder with a water-cooled, diamondtipped blade. The disks were quartered to provide quadruplicate, 32-member sample sets designated I...IV. Each concrete quarter-disk had a finished (i.e., unformed and uncut) upper surface and a smooth, diamond-cut lower surface (Figure 3).

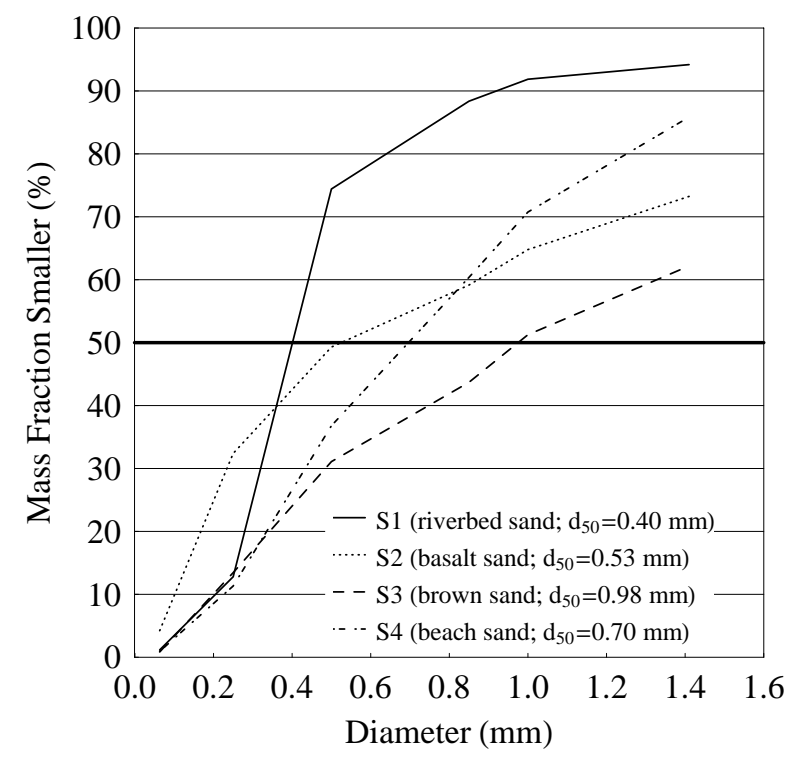

(a)

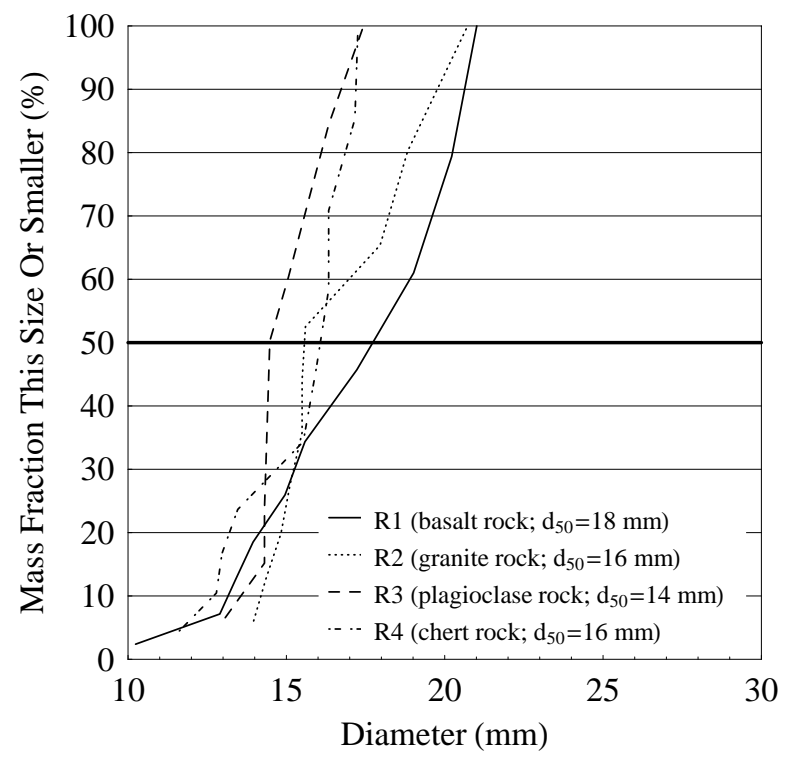

(b)

Figure 2. Sand and rock sizes. Shown are the size distributions and mass-mean diameters [ $\left.d_{50}\right]$ of (a) sands $S 1 \ldots S 4$ and (b) rocks $R 1 \ldots R 4$. 
Concrete strengths were not measured, but mixes incorporating sand S2 (basalt), sand S3 (quartz, clay minerals), rock R1 (basalt), or rock R4 (chert, iron impurities) had finished surfaces that tended to crumble easily, show rock, and/or be rough. These 24 substandard mixes will be labeled "rough," while the remaining eight mixes, which appeared solid and smooth, will be labeled "smooth." Air voids were sometimes observed at the formed bottom surfaces of the rough concrete cylinders (Figure 4).

High, unmet aggregate water demand (reducing the amount of water available to react with cement, and thereby hindering the formation of

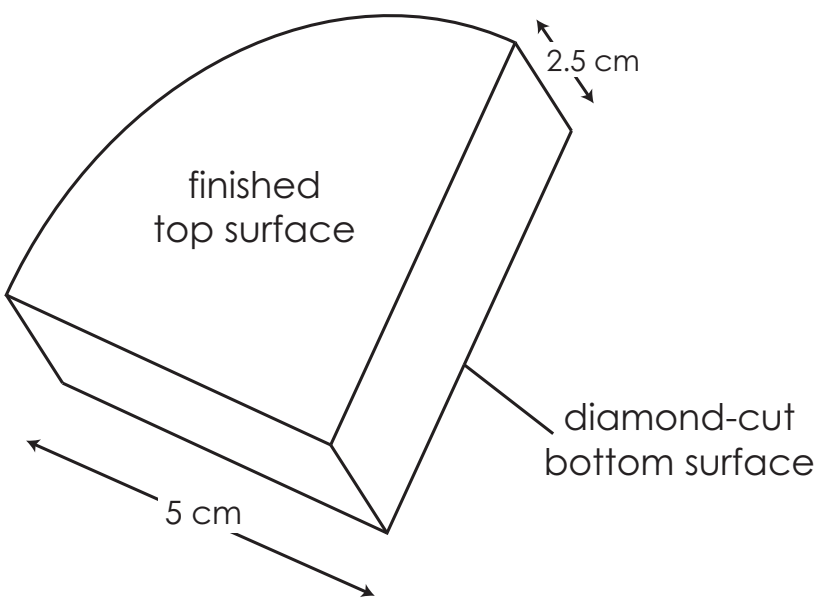

Figure 3. Surfaces of concrete sample quarter-disk.

Each sample had a finished (i.e., uncut and unmolded) top surface and a cut bottom surface. cement paste) was likely responsible for the substandard nature of the rough mixes. Attempts to create better-finished concretes by adding more water to these mixes yielded test cylinders that disintegrated when removed from their molds. Proper practice would have been to wash and thereby saturate all aggregates before casting the concretes.

\subsection{Exposure Simulations}

Each variety of concrete was subjected to the following simulations of pavement exposure processes.

Control Surfaces. The finished surfaces of quarter-disks I and II ("first-control" surface FC and "second-control" surface SC) were not exposed to processes expected to permanently change surface properties. Surface FC was kept dry, while the albedo of surface SC was measured both wet and dry to gauge the extent to which rain reduces concrete reflectance.

Formed Surfaces. The formed bottom of each cylinder ("formed" surface FO) was kept dry and unexposed.

Weathered Surfaces. The finished surface of quarter-disk III ("weathered" surface WE) was exposed to 12-hour cycles of deionized water spray, condensation, and intense ultraviolet light for six weeks to simulate the effects of dew and sunlight [ASTM Practice G154-00ae01, cycle seven: UVA $340 \mathrm{~nm}$, $1.35 \mathrm{~W} \mathrm{~m}^{-2} \mathrm{~nm}^{-1} ; 8 \mathrm{hr}$ UV light @ $60^{\circ} \mathrm{C}, 10 \mathrm{~min}$ spray, $3.75 \mathrm{hr}$ condensation @ $50^{\circ} \mathrm{C}, 5 \mathrm{~min}$ spray (ASTM 2001)]. For brevity, this combined UV, water-spray, and condensation exposure will be denoted weathering. The weathering acceleration factor for this test is unknown, but factors of 2 to 35 have been reported for exposure of polymers to similar, but not identical, cycles (Fedor and Brennan 1996). Following exposure, the albedo of surface WE was measured both wet and dry. 


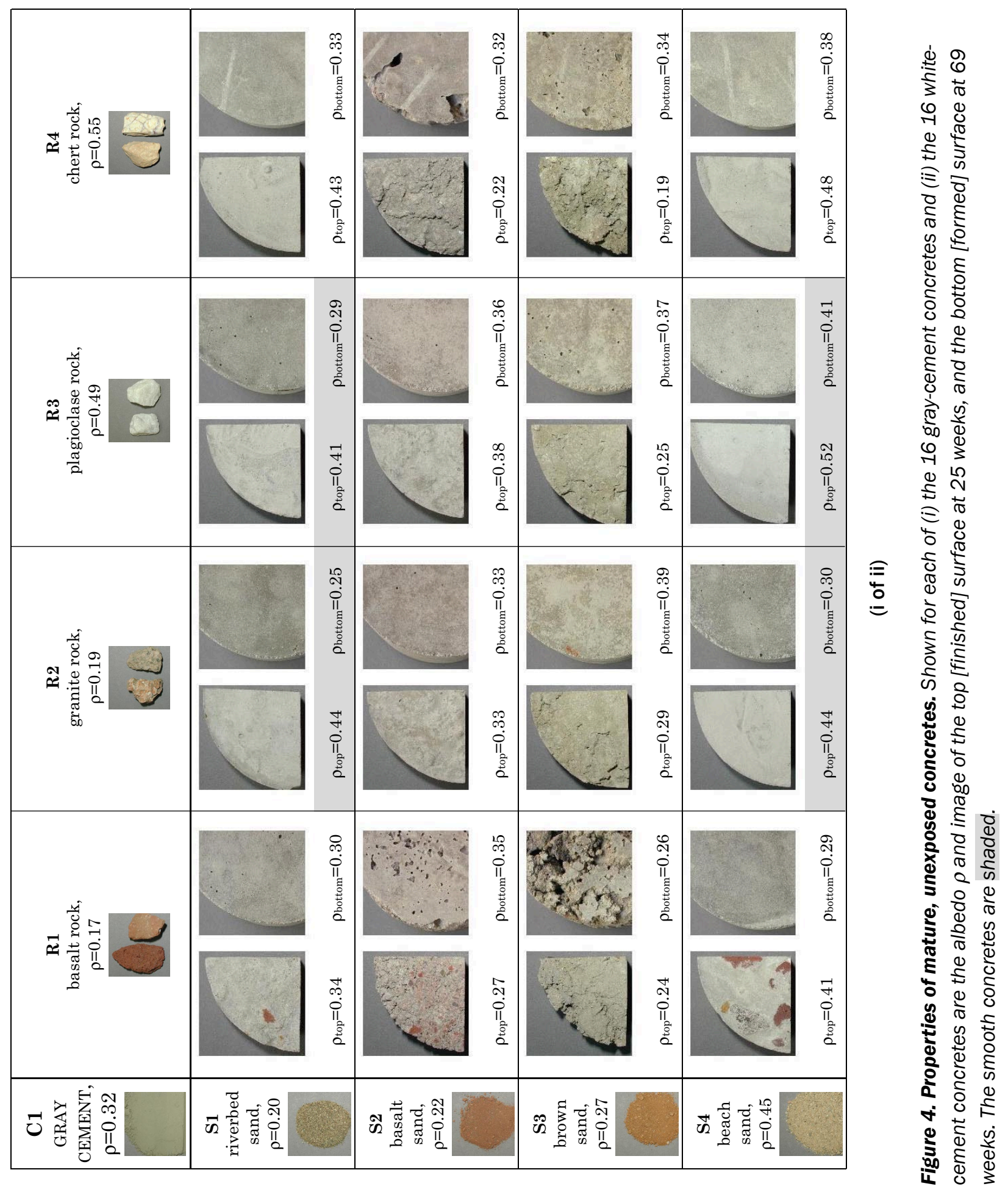




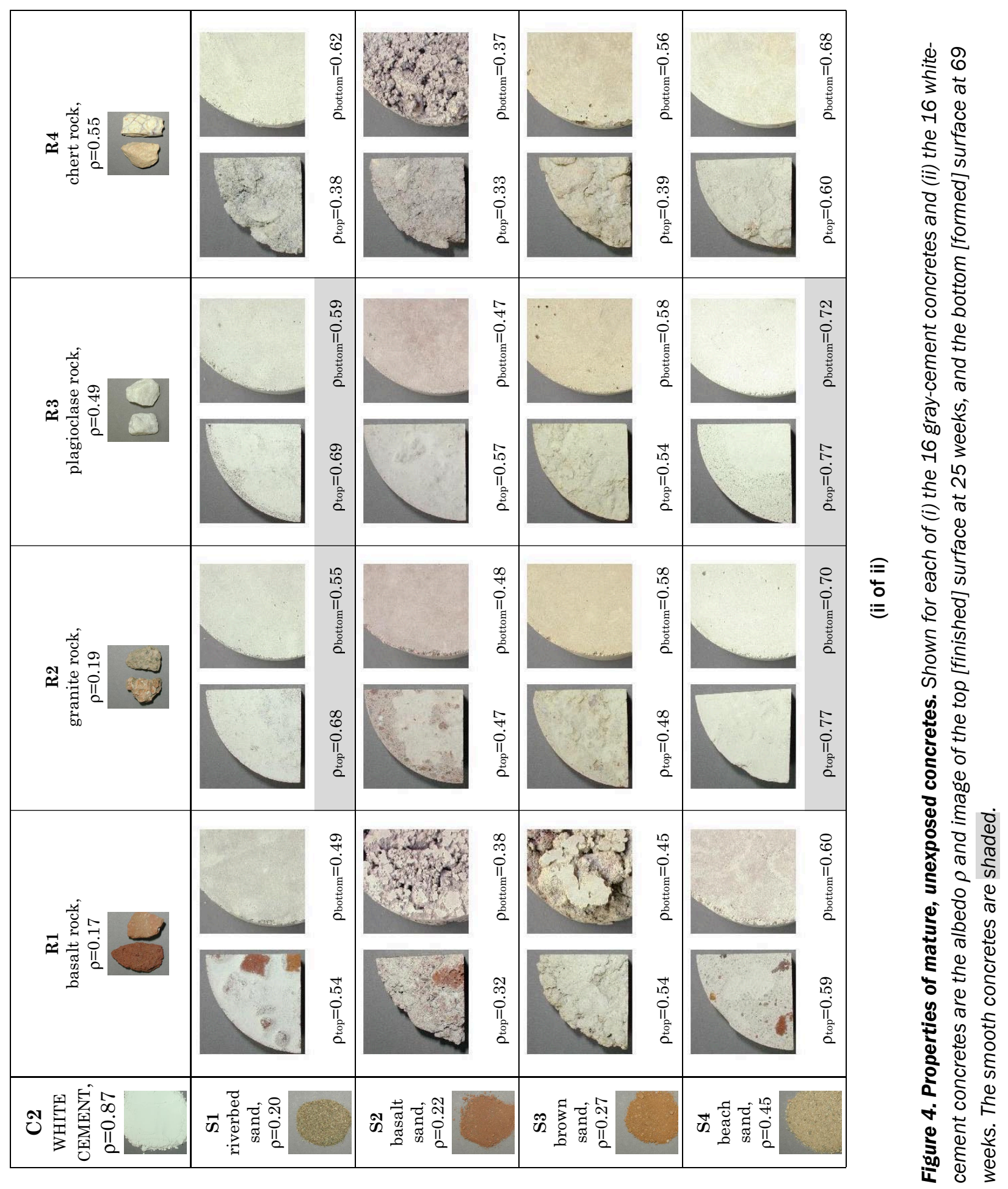


Soiled Surfaces. Pavements can be soiled by agents including dirt, oil, rubber, and carbon. Soiling was simulated by dipping the finished surface of quarter-disk IV ("soiled" surface SO) in clean motor oil, rubbing the oiled surface in sand S3, and dislodging loose sand with paper toweling. This simulation did not include soiling by rubber or carbon. Surface SO was later rinsed and dried to simulate cleaning by rain. Surfaces that were soiled, rinsed, and dried will be labeled "soiled" for brevity.

Abraded Surfaces. Tire abrasion can wear down pavement, exposing rock as mortar is dislodged. A diamond-blade cut at a depth comparable to the diameter of the rock exposes about as much rock as can be revealed by any abrasion process. Thus, the cut surface of quarter-disk II ("abraded" surface $A B, 25 \mathrm{~mm}$ below the finished surface) simulated extreme abrasion. Surface $A B$ was otherwise unexposed.

Unexposed and exposed surfaces of all 32 mixes of concrete are shown in Figure 5. Concrete albedos were measured at various times over a 69-week post-casting period chronicled in Figure 6. The $n^{\text {th }}$ measurement of the albedo of surface $X Y$ is denoted $X Y n$; e.g., $A B 1$ denotes the first measurement of the reflectance of abraded concrete surface $A B$.

\section{$3 \quad$ Results}

Aging, exposure, and composition influenced concrete albedo. The effects of aging and exposure on the full set of all 32 concrete mixes were similar to their effects on the subset of eight smooth concrete mixes. The effects of composition on concrete albedo will be presented only for the smooth concretes, since the reflectance of the rough concretes was influenced more by improper casting than by component properties.

Changes to the albedos of a set of surfaces can be characterized by the mean change $\delta$, which indicates on average whether the albedos are increasing or decreasing, and by the root-mean-square change $\chi$, which measures the average magnitude of the changes. If $\chi$ is zero, no albedos have changed. If $\delta$ is zero but $\chi$ is finite, increases and decreases have cancelled on average. The subscript "s" will be used to denote properties of the set of eight smooth mixes, and the subscript "a" to denote the set of all 32 mixes. 


\begin{tabular}{|c|c|c|c|c|c|c|}
\hline Concrete & $\begin{array}{l}\text { (a) Unexposed } \\
@ 25 \text { weeks } \\
(F C 2)\end{array}$ & $\begin{array}{l}\text { (b) Weathered } \\
@ 25 \text { weeks } \\
\text { (WE5) }\end{array}$ & $\begin{array}{l}\text { (c) Weathered, } \\
\text { wetted @ 20 } \\
\text { weeks (WE4) }\end{array}$ & $\begin{array}{l}\text { (d) Soiled @ } 35 \\
\text { weeks (SO4) }\end{array}$ & $\begin{array}{l}\text { (e) Abraded @ } 25 \\
\text { weeks }(A B 2)\end{array}$ & $\begin{array}{r}\text { (f) Formed @ } 69 \\
\text { weeks (FO1) }\end{array}$ \\
\hline \multirow[t]{2}{*}{$\begin{array}{c}\text { C1:S1:R1 } \\
\text { gray cement/ } \\
\text { riverbed sand/ } \\
\text { basalt rock }\end{array}$} & & & & & & \\
\hline & $\rho=0.34$ & $\rho=0.27$ & $\rho=0.18$ & $\rho=0.38$ & $\rho=0.13$ & $\rho=0.30$ \\
\hline \multirow[t]{2}{*}{$\begin{array}{l}\text { C1:S1:R2 } \\
\text { gray cement/ } \\
\text { riverbed sand/ } \\
\text { granite rock }\end{array}$} & & & & & & \\
\hline & $\rho=0.44$ & $\rho=0.34$ & $\rho=0.14$ & $\rho=0.43$ & $\rho=0.24$ & $\rho=0.25$ \\
\hline \multirow[t]{2}{*}{$\begin{array}{l}\text { C1:S1:R3 } \\
\text { gray cement/ } \\
\text { riverbed sand/ } \\
\text { plagioclase rock }\end{array}$} & & & & & & \\
\hline & $\rho=0.41$ & $\rho=0.30$ & $\rho=0.13$ & $\rho=0.36$ & $\rho=0.31$ & $\rho=0.29$ \\
\hline \multirow[t]{2}{*}{$\begin{array}{l}\text { C1:S1:R4 } \\
\text { gray cement/ } \\
\text { riverbed sand } \\
\text { chert rock }\end{array}$} & & & & & & \\
\hline & $\rho=0.43$ & $\rho=0.36$ & $\rho=0.22$ & $\rho=0.41$ & $\rho=0.55$ & $\rho=0.33$ \\
\hline \multirow[t]{2}{*}{$\begin{array}{l}\text { C1:S2:R1 } \\
\text { gray cement/ } \\
\text { basalt sand/ } \\
\text { granite rock }\end{array}$} & & & & & & \\
\hline & $\rho=0.27$ & $\rho=0.23$ & $\rho=0.14$ & $\rho=0.27$ & $\rho=0.25$ & $\rho=0.35$ \\
\hline \multirow[t]{2}{*}{$\begin{array}{c}\text { C1:S2:R2 } \\
\text { gray cement/ } \\
\text { basalt sand/ } \\
\text { granite rock }\end{array}$} & & & & & & \\
\hline & $\rho=0.33$ & $\rho=0.25$ & $\rho=0.12$ & $\rho=0.33$ & $\rho=0.24$ & $\rho=0.33$ \\
\hline \multirow[t]{2}{*}{$\begin{array}{c}\text { C1:S2:R3 } \\
\text { gray cement/ } \\
\text { basalt sand/ } \\
\text { plagioclase rock }\end{array}$} & & & & & & \\
\hline & $\rho=0.38$ & $\rho=0.30$ & $\rho=0.15$ & $\rho=0.36$ & $\rho=0.33$ & $\rho=0.36$ \\
\hline \multirow[t]{2}{*}{$\begin{array}{c}\text { C1:S2:R4 } \\
\text { gray cement/ } \\
\text { basalt sand/ } \\
\text { chert rock }\end{array}$} & & & & & & \\
\hline & $\rho=0.22$ & $\rho=0.23$ & $\rho=0.11$ & $\rho=0.26$ & & \\
\hline
\end{tabular}

(i of iv)

Figure 5. Properties of all mature concretes. Images and albedos $[\rho]$ of all 32 mixes of concrete are shown (a) unexposed, (b) weathered, (c) weathered and wetted, (d) soiled, (e) abraded, and (f) formed. Smooth concretes are shaded. 


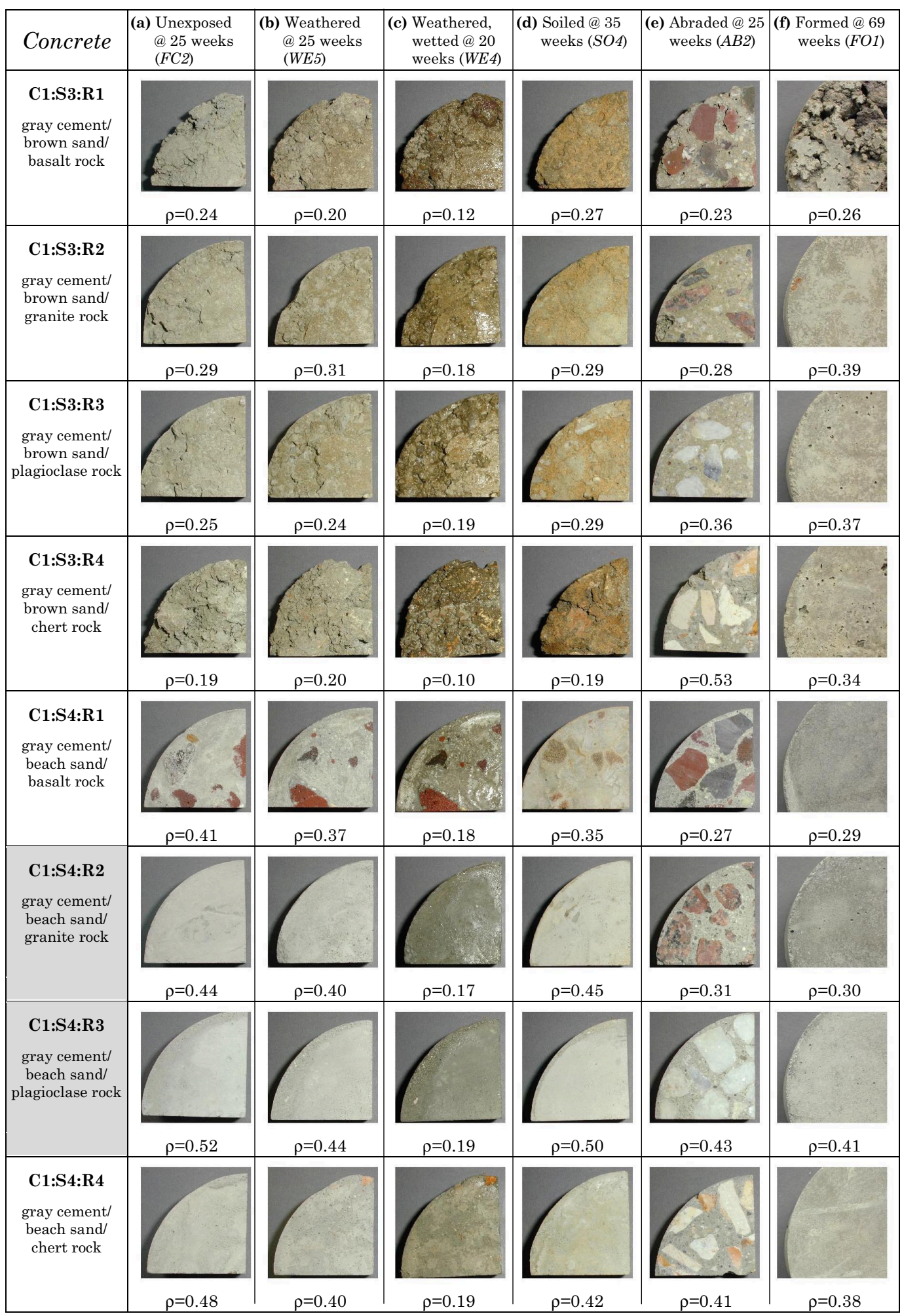

(ii of iv)

Figure 5. Properties of all mature concretes. Images and albedos [ $\rho$ ] of all 32 mixes of concrete are shown (a) unexposed, (b) weathered, (c) weathered and wetted, (d) soiled, (e) abraded, and (f) formed. Smooth concretes are shaded. 


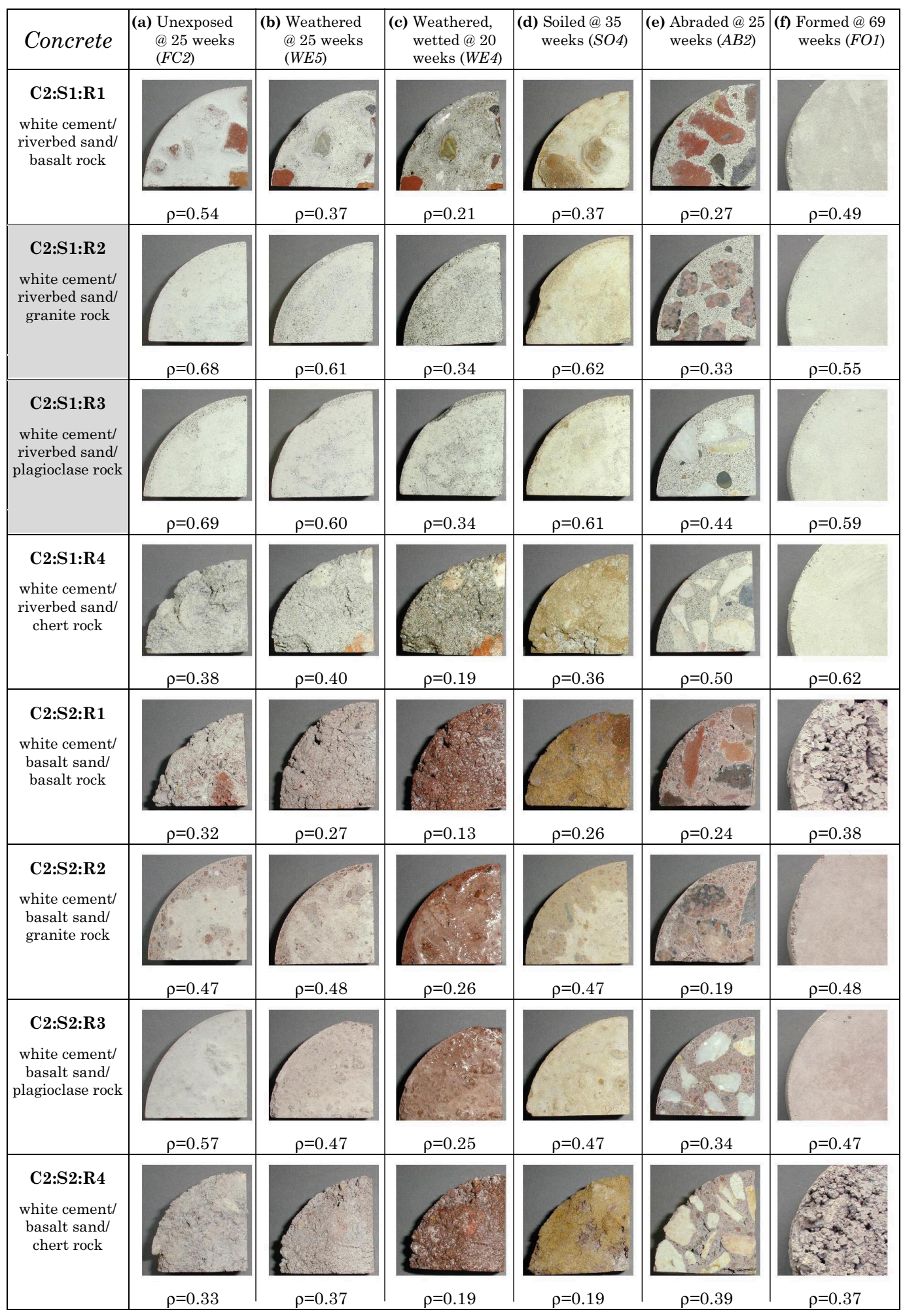

(iii of iv)

Figure 5. Properties of all mature concretes. Images and albedos $[\rho]$ of all 32 mixes of concrete are shown (a) unexposed, (b) weathered, (c) weathered and wetted, (d) soiled, (e) abraded, and (f) formed. Smooth concretes are shaded. 


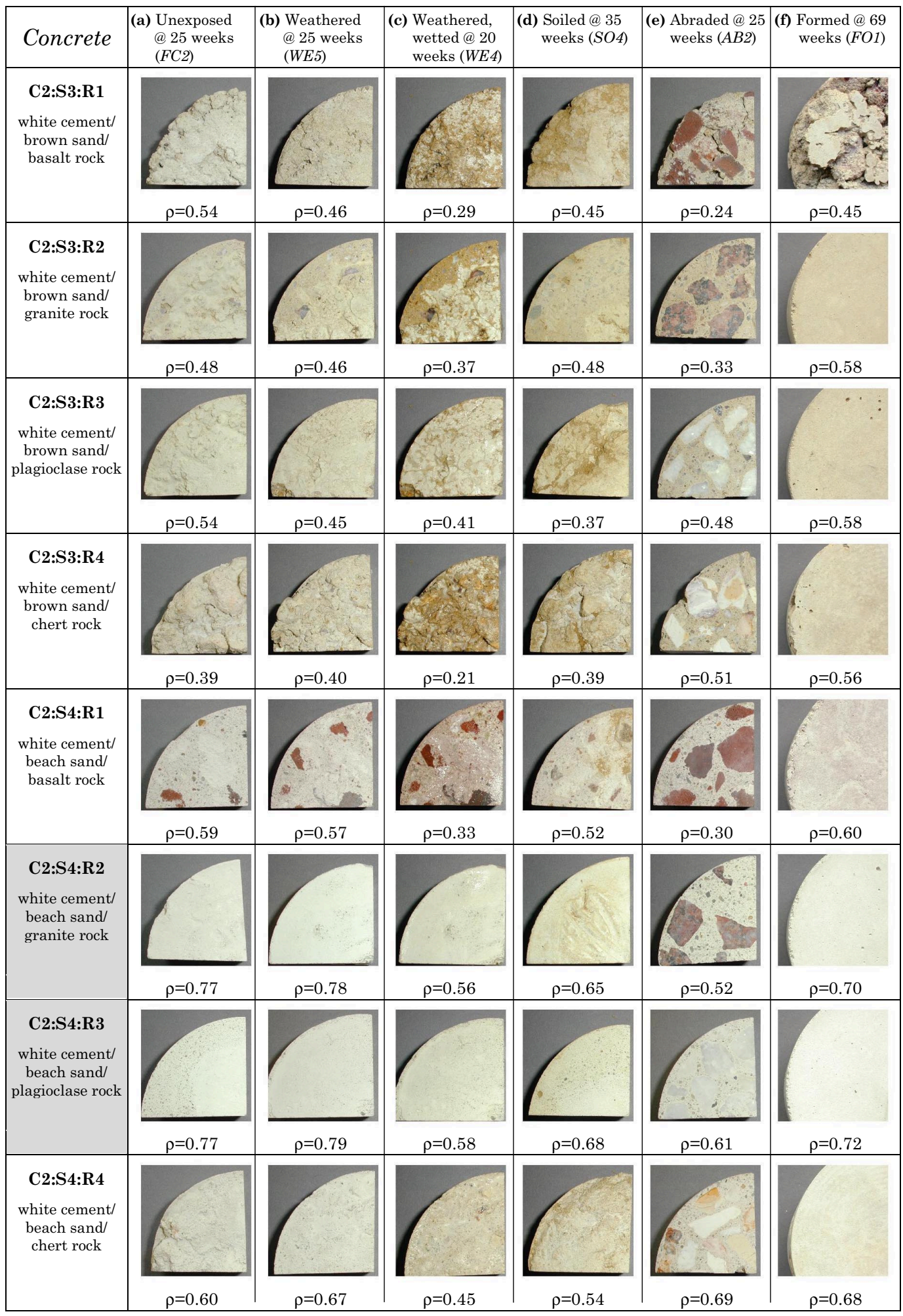

(iv of iv)

Figure 5. Properties of all mature concretes. Images and albedos $[\rho]$ of all 32 mixes of concrete are shown (a) unexposed, (b) weathered, (c) weathered and wetted, (d) soiled, (e) abraded, and (f) formed. Smooth concretes are shaded. 


\subsection{Concrete Albedo Vs. Time}

Isolating the influence of exposure on albedo was complicated by the tendencies of most concretes to become more reflective as they cured. Nearly all unexposed concretes were significantly more reflective at week six than at week one (measurement FC1 vs. measurement WE1: smooth-mix change $\delta_{s}=0.08, \chi_{s}=0.13$; all-mix change $\delta_{a}=0.12, \chi_{a}=0.15$ ) (Figure 7). However, the albedos of unexposed concretes stabilized within six weeks of casting, increasing only slightly from weeks six to 25 (FC2 vs. FC1: $\delta_{\mathrm{s}}=0.01, \chi_{\mathrm{s}}=0.02 ; \delta_{\mathrm{a}}=0.01, \chi_{\mathrm{a}}=0.03$ ) (Figure 8), and even less from weeks 25 to 35 (FC3 vs. FC2: $\delta_{\mathrm{s}}=0.00, \chi_{\mathrm{s}}=0.01 ; \delta_{\mathrm{a}}=0.00, \chi_{\mathrm{a}}=0.02$ ). Concretes whose albedos have stabilized will be denoted "mature." The rate of albedo growth in immature concretes varied from set to set, and was influenced by changes to water content induced by surface wetting and drying (Appendix A).

The reflectance difference between white-cement concretes and gray-cement concretes widened as concretes matured because the albedos of white-cement concretes increased more than did those of gray-cement concretes. The albedo distributions of immature and mature unexposed concretes are shown in Figure $\mathbf{9}$ and Figure 10, respectively.

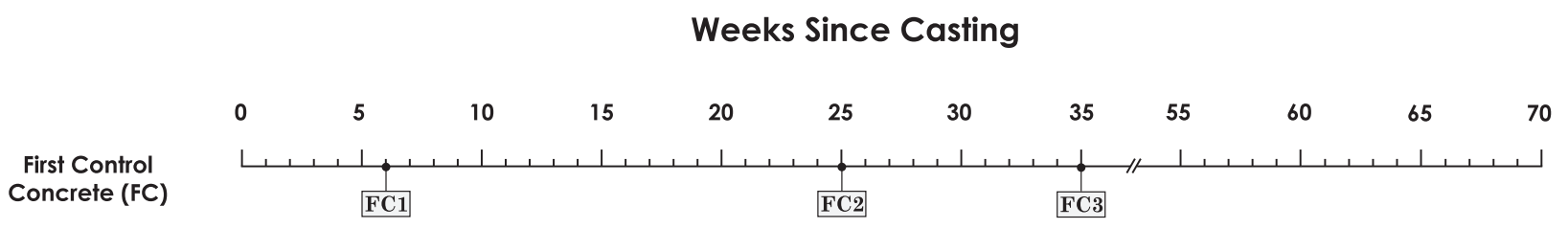

Second Control Concrete (SC)

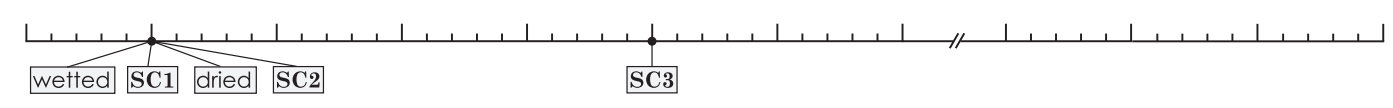

Weathered

Concrete (WE)
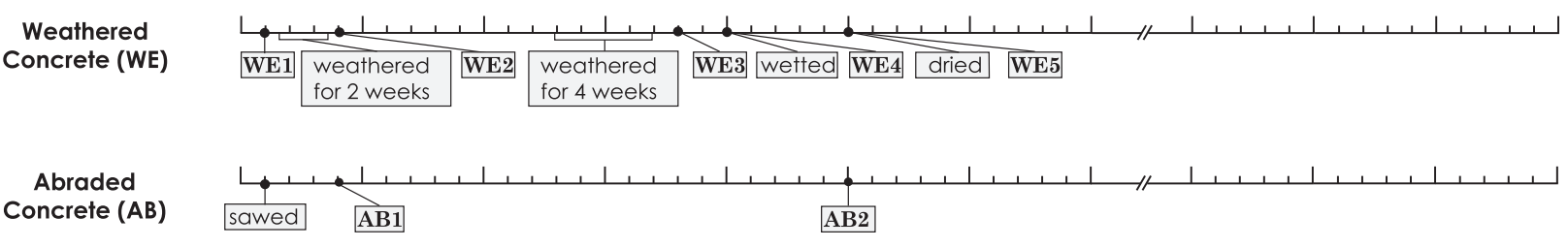

Soiled
Concrete (SO)

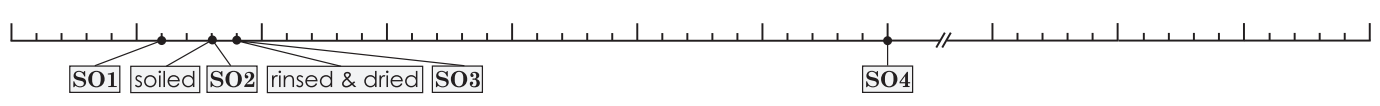

Formed Concrete (FO)

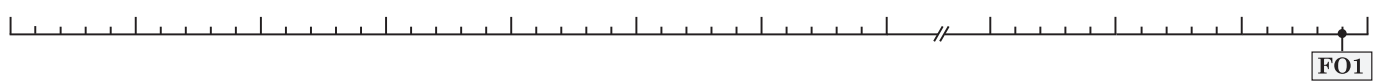

Figure 6. Experiment timeline. Shown are the exposure and reflectance-measurement histories of six concrete-surface sets. Labels of the form AB1 denote albedo measurements. 


\subsection{Concrete Albedo Vs. Exposure}

The mature albedos of the unexposed control concretes (FC2) ranged from 0.41 to 0.77 (mean 0.59 ) for smooth mixes, and from 0.19 to 0.77 (mean 0.45) for all mixes (Figure 10). All exposure processes reduced the mean albedo of the set of smooth mixes, and that of the set of all mixes. However, the reflectances of some mixes were slightly increased by weathering or soiling, and some rough mixes were made more reflective by abrasion. Before exposure, the albedos of the white-cement concretes were on average appreciably more reflective than those of their corresponding graycement concretes $\left(\delta_{s, w-g}=0.27 ; \delta_{a, w-g}=0.19\right)$. Two exposure processes (soiling and abrasion) lowered the albedos of white-cement concretes more than those of gray-cement concretes, reducing the mean white-gray difference, while a third process (weathering) slightly increased the gap.

Weathering. On average, weathered concretes were somewhat less reflective than unexposed concretes (WE5 vs. FC2: $\delta_{s}=-0.06, \chi_{s}=0.07 ; \delta_{a}=-0.04, \chi_{a}=0.07$ ) (Figure 11a). Weathering tended to reduce the reflectances of gray-cement concretes more than it did those of white-cement concretes, slightly widening the mean white-gray difference $\left(\delta_{s, w-g}=0.32 ; \delta_{a, w-g}=0.21\right.$ ).

Soiling. On average, soiled (and rinsed and dried) concretes were also somewhat less reflective than unexposed concretes (SO4 vs. FC2: $\delta_{\mathrm{s}}=-0.05, \chi_{\mathrm{s}}=0.07 ; \delta_{\mathrm{a}}=-0.04, \chi_{\mathrm{a}}=0.07$ ) (Figure 11b). This process had little effect on the mean albedo of gray-cement concretes, but appreciably lowered that of white-

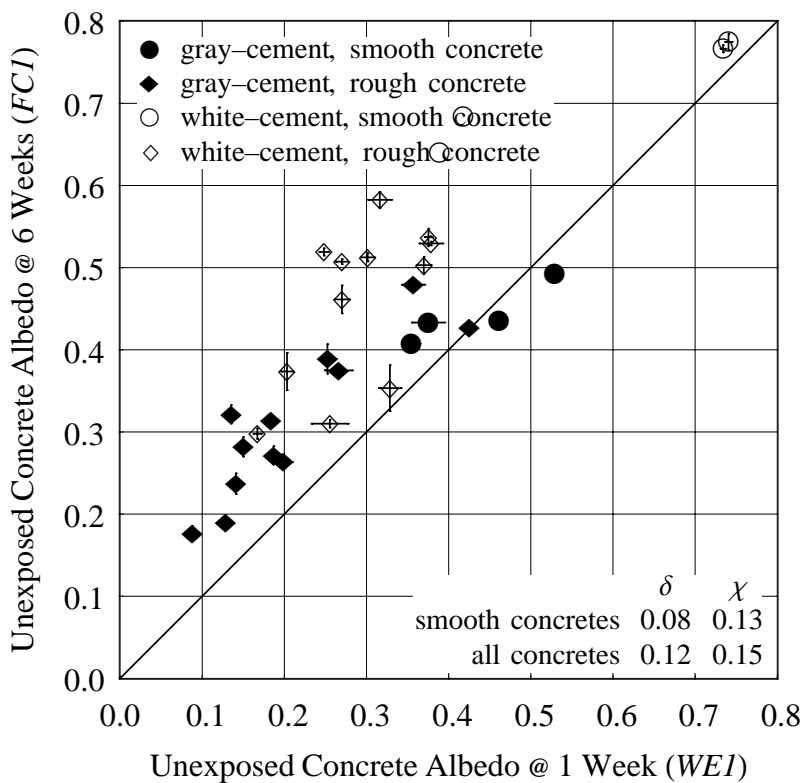

Figure 7. Concrete albedo growth. The albedos of most unexposed concretes increased from week one to week six. $\delta$ and $\chi$ are mean and root-mean-square differences in albedo; the diagonal line marks equality.

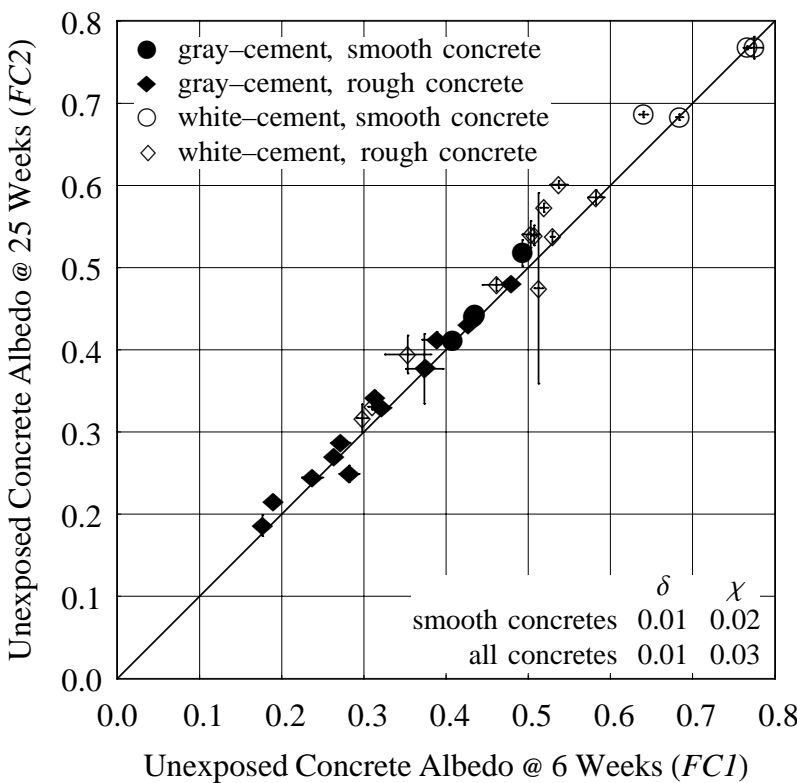

Figure 8. Concrete albedo stabilization. The albedos of unexposed concretes increased very slowly after week six. 
cement concretes, narrowing the mean white-gray difference $\left(\delta_{s, w-g}=0.19 ; \delta_{a, w-g}=0.12\right)$. Rinsing and drying only slightly increased the mean albedo of the soiled surfaces (SO3 vs. SO2: $\delta_{s}=0.03$, $\left.\chi_{\mathrm{s}}=0.03 ; \delta_{\mathrm{a}}=0.02, \chi_{\mathrm{a}}=0.04\right)$ (Figure 12).

Abrasion. The abraded concretes were on average noticeably less reflective than the unexposed concretes ( $A B 2$ vs. FC2: $\delta_{s}=-0.19, \chi_{s}=0.21 ; \delta_{a}=-0.08, \chi_{a}=0.18$ ) (Figure 11c). Abrasion lowered the mean albedo of white-cement concretes much more than it did that of gray-cement concretes, shrinking the mean white-gray difference $\left(\delta_{s, w-g}=0.15 ; \delta_{a, w-g}=0.07\right)$. Some rough concretes became more reflective, probably because their abraded surfaces were much flatter than their finished surface.

Wetting. Wetting made most of the weathered surfaces significantly less reflective (WE4 vs. WE5: $\delta_{s}=-0.23, \chi_{s}=0.23 ; \delta_{a}=-0.17, \chi_{a}=0.18$ ) (Figure 11d), and slightly changed the mean white-gray difference, increasing it for the set of smooth concretes and decreasing it for the set of all concretes $\left(\delta_{s, w-g}=0.30 ; \delta_{a, w-g}=0.16\right)$.

\subsection{Concrete Albedo Vs. Composition}

The mature albedos of unexposed and abraded concretes were generally bounded by the albedos of their least and most reflective components, with a few exceptions attributable to frosting.

Cement. The albedo of unexposed, smooth concrete increased with cement albedo for all four combinations of sand and rock (Figure 13a); the same was true after weathering, soiling, and abrasion (Appendix B). The four most-reflective, unexposed, smooth concretes ( $\rho=0.68$ to 0.77 ) were made with white cement; the four least-reflective, unexposed, smooth concretes ( $\rho=0.44$ to 0.52 ) were made with gray cement (Figure 10).

Sand. The albedo of unexposed, smooth concrete increased with sand albedo for three out of four combinations of cement and rock (Figure 13b); in the exceptional case, the concrete made with the less-reflective sand was frosted. After weathering, soiling, and abrasion, smooth concrete albedo correlated with sand albedo for all four combinations of cement and rock (Appendix B).

Rock. The albedo of unexposed, smooth concrete did not vary appreciably with rock albedo for two combinations of cement and sand; increased with rock albedo for a third combination; and decreased with rock albedo for a fourth combination (Figure 13c). The same was true after weathering, soiling, and abrasion (Appendix B). As expected, the albedo of abraded, smooth concrete correlated with rock albedo for all four combinations (Figure 13d). 


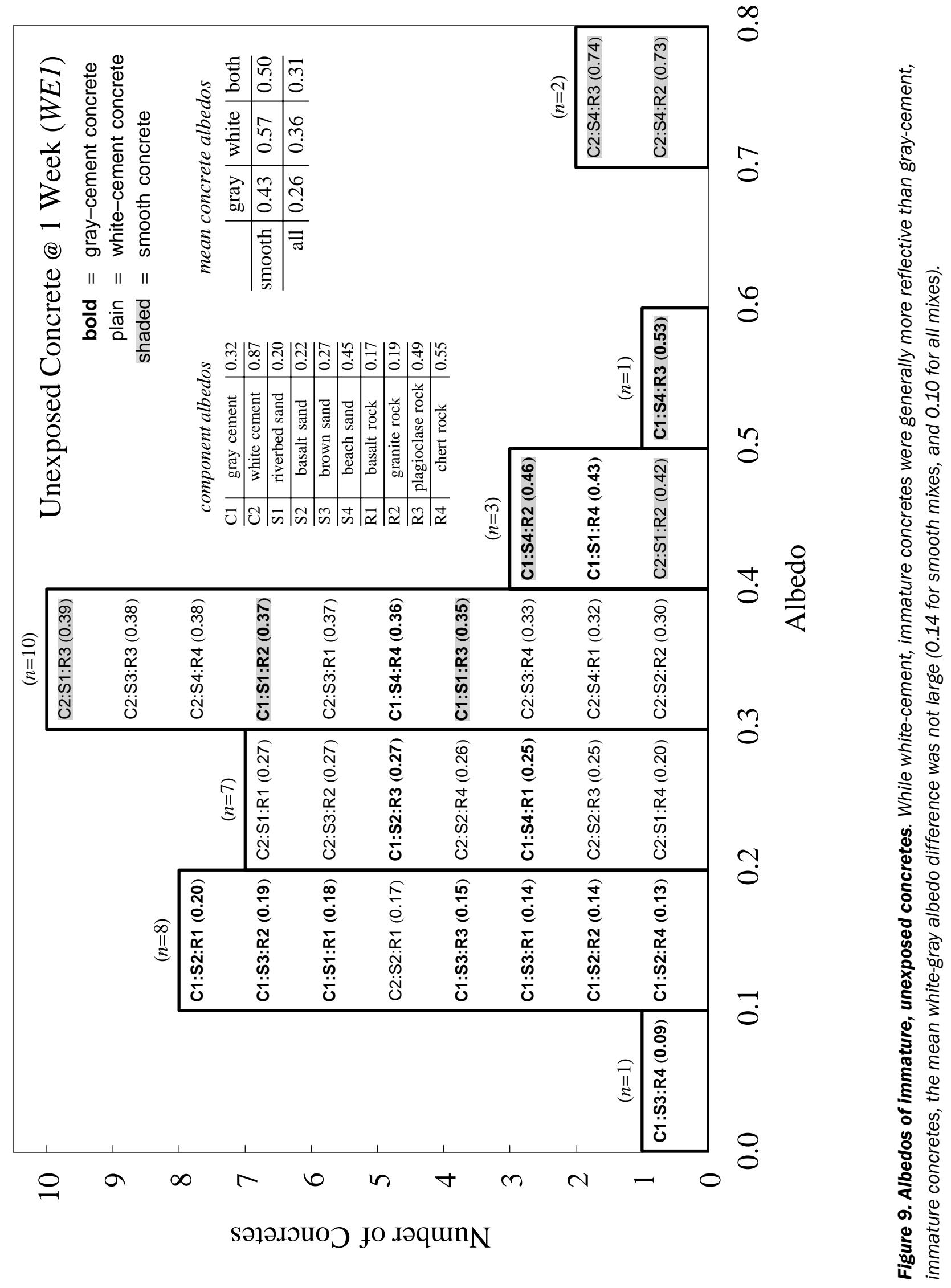




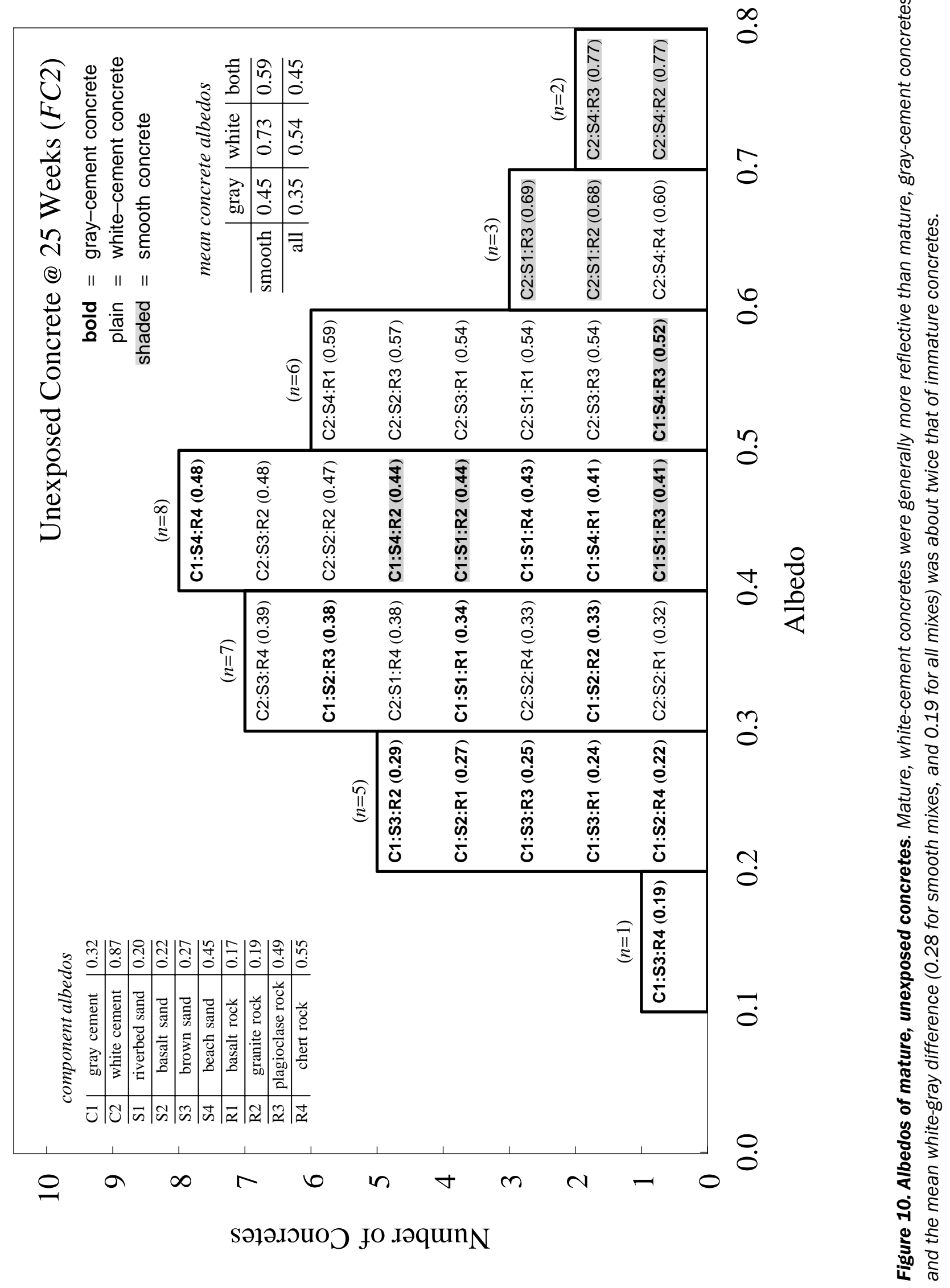




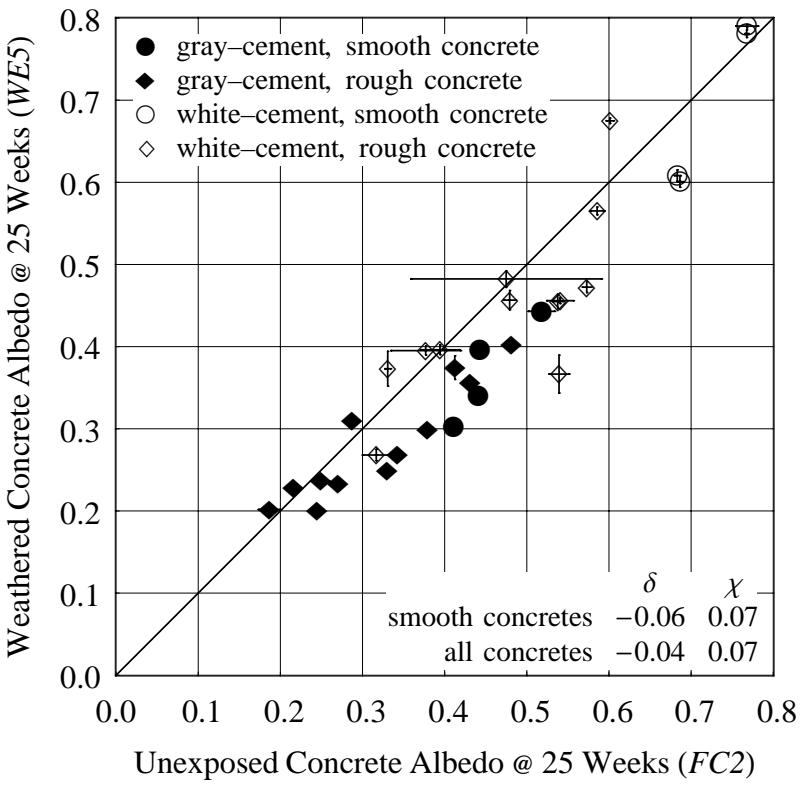

(a)

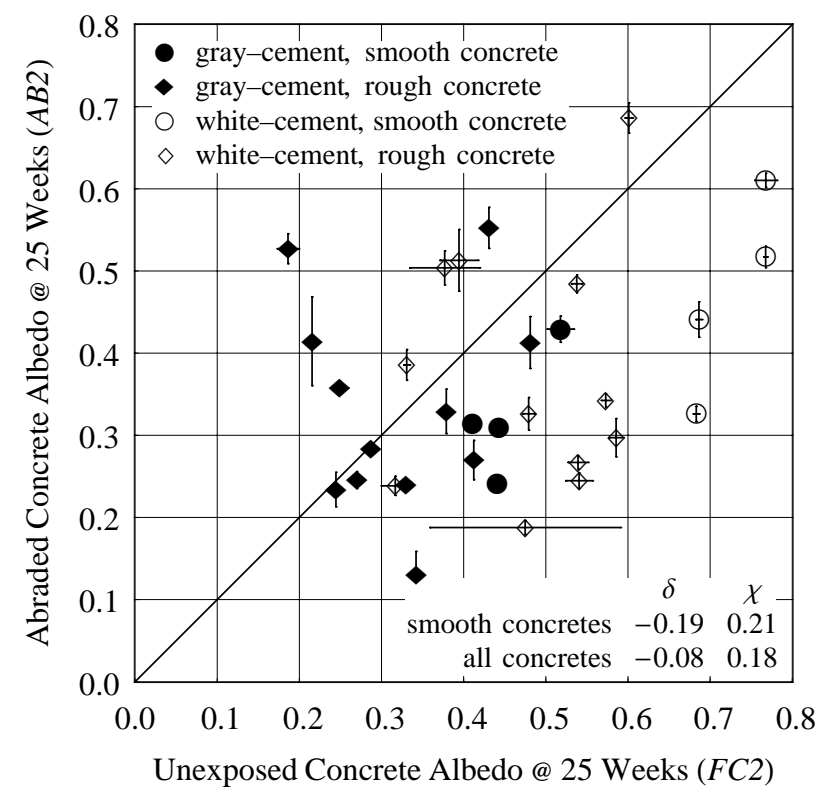

(c)

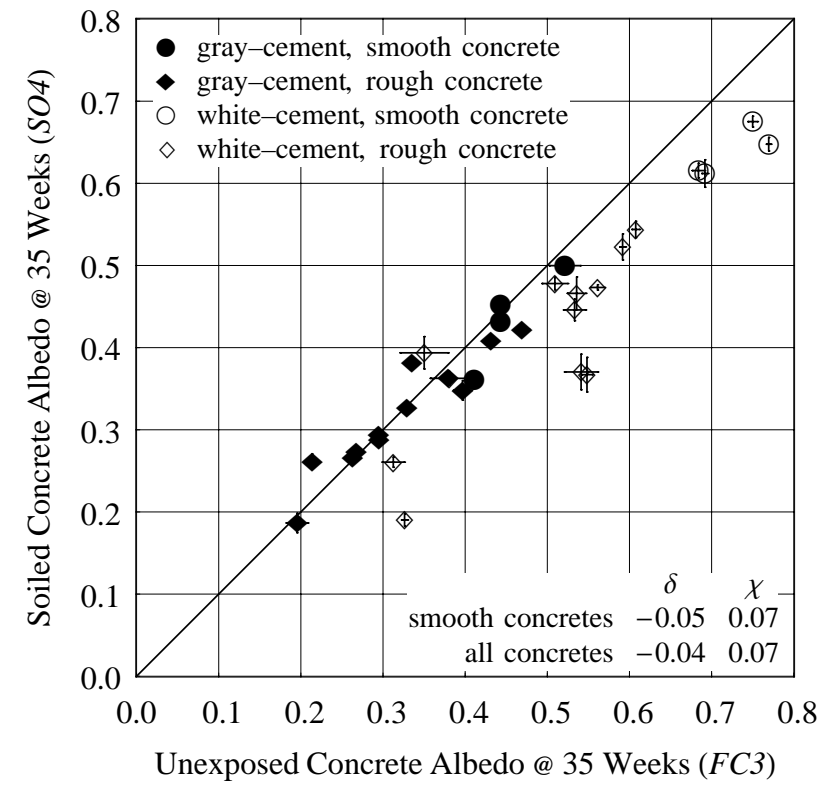

(b)

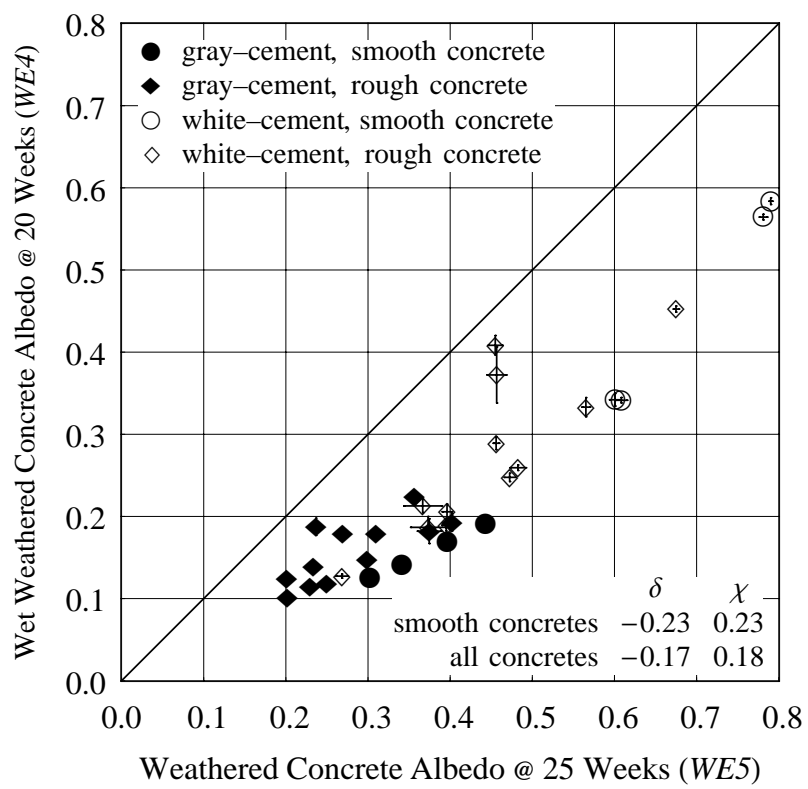

(d)

Figure 11. Mature concrete albedo vs. exposure. Exposure to (a) weathering, (b) soiling, and (c) abrasion moderately reduced mean albedos, while (d) wetting made all concretes less reflective. Note that charts (a) through (c) each compare two different sample sets (e.g., soiled set SO vs. first-control set FC), while chart (d) compares two different states of the same sample set (weathered set WE). 
Table 4. Correlation of smooth-concrete albedo to component albedo. Cement, sand, and rock albedo correlation estimates $k_{c}, k_{s}$, and $k_{r}$ and their standard errors (in parentheses) are shown for unexposed, weathered, soiled, and abraded smooth concretes. The $k_{0}$ term accounts for all other factors. Results should not be used predictively because the number of samples is small $(n=8)$.

\begin{tabular}{|c|c|c|c|c|c|c|}
\hline state & $k_{c}$ & $k_{s}$ & $k_{r}$ & $k_{0}$ & adj. $R^{2}$ & regression model \\
\hline unexposed & $\begin{array}{c}0.50 \\
(0.03)\end{array}$ & $\begin{array}{c}0.28 \\
(0.08)\end{array}$ & & $\begin{array}{c}0.20 \\
(0.03)\end{array}$ & 0.97 & \multirow{3}{*}{$\rho_{\text {concrete }}=k_{c} \rho_{c}+k_{s} \rho_{s}+k_{0}$} \\
\hline weathered & $\begin{array}{c}0.59 \\
(0.04)\end{array}$ & $\begin{array}{c}0.57 \\
(0.09)\end{array}$ & & $\begin{array}{c}0.00 \\
(0.04)\end{array}$ & 0.97 & \\
\hline soiled & $\begin{array}{c}0.37 \\
(0.04)\end{array}$ & $\begin{array}{c}0.26 \\
(0.09)\end{array}$ & & $\begin{array}{c}0.24 \\
(0.04)\end{array}$ & 0.93 & \\
\hline abraded & $\begin{array}{c}0.27 \\
(0.04)\end{array}$ & $\begin{array}{c}0.55 \\
(0.10)\end{array}$ & $\begin{array}{c}0.33 \\
(0.08)\end{array}$ & $\begin{array}{l}-0.06 \\
(0.05)\end{array}$ & 0.99 & $\rho_{\text {concrete }}=k_{c} \rho_{c}+k_{s} \rho_{s}+$ \\
\hline
\end{tabular}

Relative Influences. Concrete albedo $\rho_{\text {concrete }}$ was regressed to cement albedo $\rho_{c}$ and sand albedo $\rho_{s}$ for the unexposed, weathered, and soiled smooth concretes; and also to that of rock albedo $\rho_{r}$ for the abraded smooth concretes. (The variation of smooth concrete albedo with rock albedo was statistically significant only after abrasion.) That is, smooth concrete albedo was modeled by

$$
\rho_{\text {concrete }}=k_{c} \rho_{c}+k_{s} \rho_{s}+k_{r} \rho_{r}+k_{0}
$$

where cement, sand, and rock albedo correlation estimates $k_{c}, k_{s}$, and $k_{r}$ each measure the influence on concrete albedo of component albedo; and constant term $k_{0}$ measures the net influence on concrete albedo of all other factors, such as cement hydration, frosting, weathering, and/or soiling. Rock albedo correlation estimate $k_{r}$ was set to zero for unabraded concretes.

Cement albedo had nearly twice the influence of sand albedo on the reflectance of unexposed smooth concrete, even though each concrete mix contained more than twice as much sand as cement. After weathering or soiling, the influence of sand albedo was comparable to that of cement albedo. After abrasion, the influence of rock albedo was comparable to that of cement albedo, but only about half that of sand albedo (Table 4). It was disproportionately low, since each mix contained more rock than sand or cement $(2.8 / 2.3 / 1$ by mass). These results should not be used predictively since the sample size $n=8$ is small.

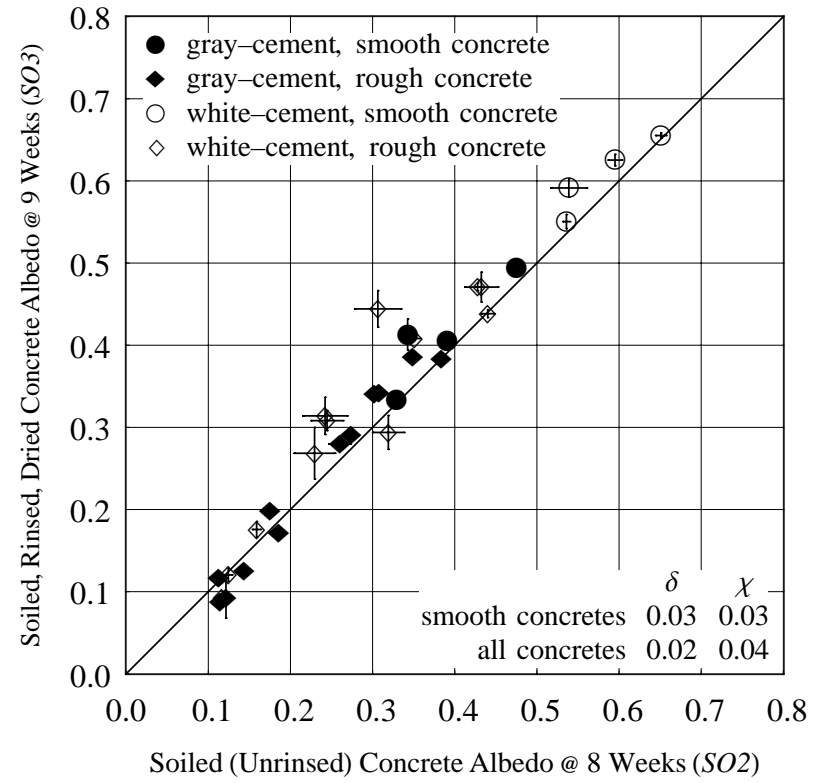

Figure 12. Rinsing soiled concretes. Rinsing and drying made soiled surfaces slightly more reflective (SO3 vs. SO2). 
$\mathrm{C} 1$

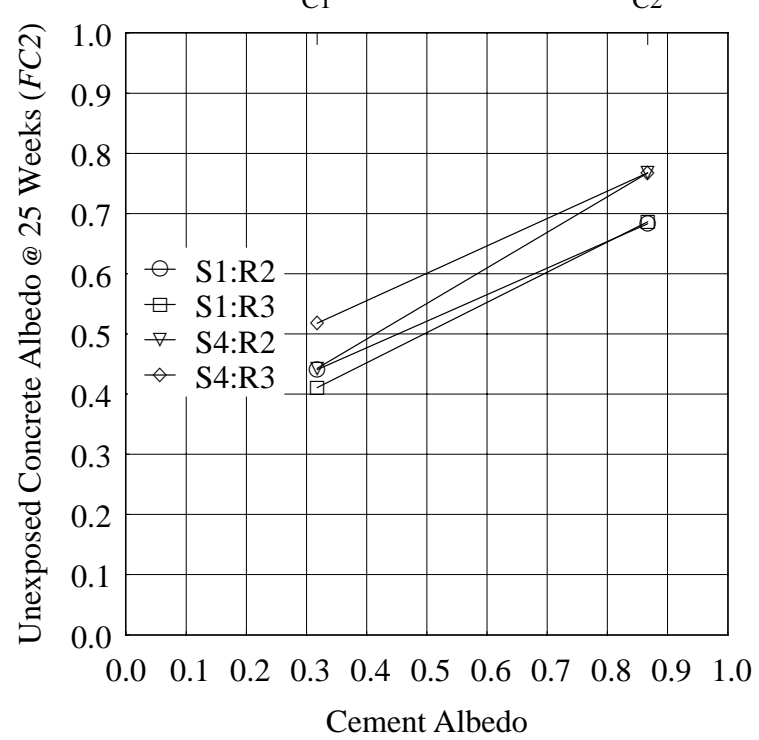

(a)

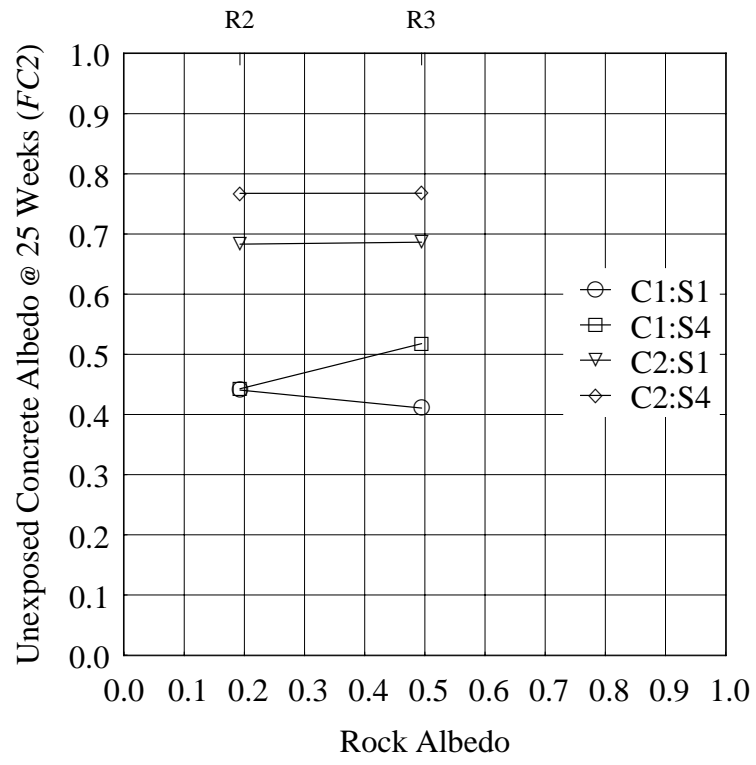

(c)

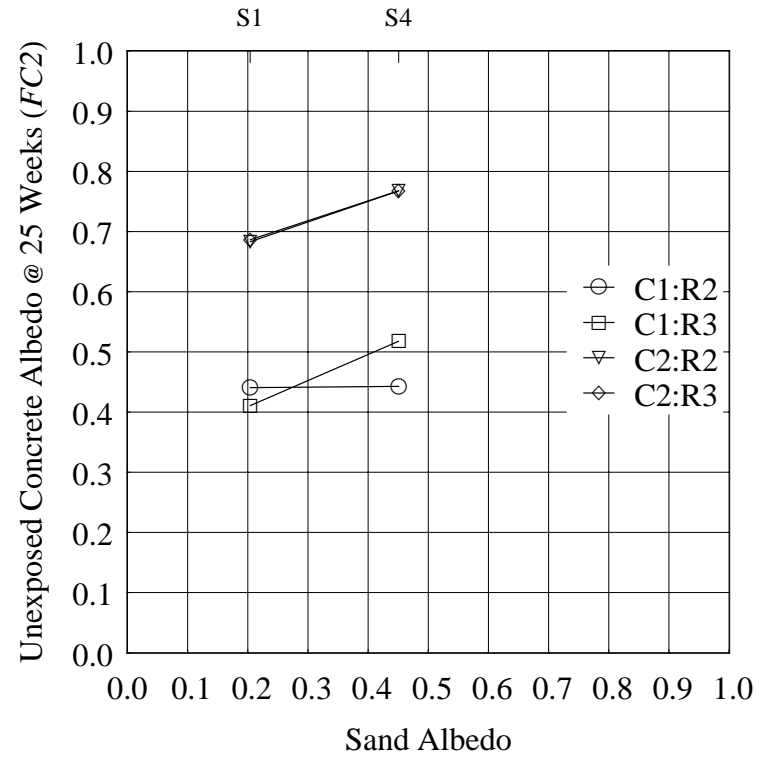

(b)

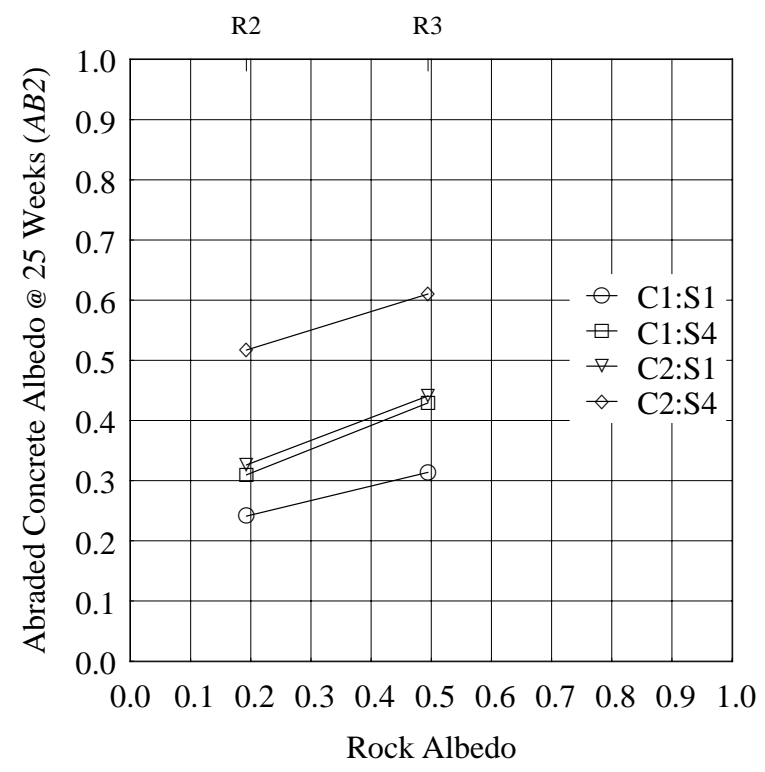

(d)

Figure 13. Mature, smooth concrete albedo vs. composition. The albedo of unexposed, mature, smooth concrete correlated with (a) cement albedo and (b) sand albedo, but not (c) rock albedo. However, the albedo of (d) abraded, mature, smooth concrete correlated with rock albedo. Lines connecting data points should not be used for interpolation. 


\section{Discussion}

Several important trends emerged from the variations of concrete albedo with aging, exposure, and composition.

Aging. Unexposed concretes generally became more reflective in the early stages of curing, stabilizing by week six (and possibly earlier, since the albedos of unexposed concretes were not measured between weeks one and six). Wetting and drying the concretes affected the hydration process and hence the rate of albedo change.

Exposure. Weathering, abrasion, and soiling each reduced the albedo of most concrete mixes, while wetting made all less reflective. However, since the first three processes were simulated arbitrarily, they do not necessarily represent real-world pavement exposures. Weathering narrowly increased and abrasion and soiling each slightly decreased the mean albedo difference between white-cement and gray-cement concretes.

Composition. The reflectance of smooth concrete generally correlated with cement albedo, sand albedo, and, after abrasion, with rock albedo. However, concrete reflectance did not increase with sand reflectance when the concrete made with the less-reflective sand was frosted. Also, the influence of component albedo on smooth concrete albedo was not proportional to each component's mass fraction.

\subsection{Reflectance as an Indicator Of Cement and Concrete Chemistry}

Calcium hydroxide $\left[\mathrm{Ca}(\mathrm{OH})_{2}\right]$ produced in the cement hydration process constitutes about $25 \%$ of the mass of a fully hydrated cement (Brunauer and Copeland 1964). This white compound can be carried to the surface by non-chemically-bound water in wet concrete ("primary efflorescence"), or leached to the surface by the penetration of rainwater into dry concrete ("secondary efflorescence"). Reaction with atmospheric carbon dioxide ("carbonation") can convert the water-soluble calcium hydroxide to white calcium carbonate $\left[\mathrm{CaCO}_{3}\right]$ within months. Calcium carbonate is insoluble, but can gradually react with carbon dioxide and water to form white, water-soluble calcium bicarbonate $\left[\mathrm{Ca}\left(\mathrm{HCO}_{3}\right)_{2}\right]$. This process can take years (Kenney 1996). Hence, the "frost" on a concrete surface can begin as effloresced calcium hydroxide, convert to calcium carbonate, and slowly become soluble calcium bicarbonate. Frosting can largely disappear within a few years in climates characterized by frequent alternation of rain and sunshine (Bayer Corporation 1997).

Cement hydration, efflorescence, and carbonation were all observed to influence concrete reflectance. First, concrete albedo increased significantly within six weeks of casting, and then stabilized, which is consistent with the hydration-reaction time constant of 20 days reported by Papadakis and Vayenas (1991). Second, white efflorescence appeared on some of the gray-cement concrete sur- 
faces within a week of casting. Third, the reflectances of concretes aged 18 to 35 weeks did not change appreciably when wetted and dried. That rinsing did not change reflectance suggests that the white surface films had been converted to insoluble calcium carbonate.

\subsection{Making High-Albedo Concrete: White Cement Vs. Gray Cement}

It is difficult to make general statements about the costs of the sands and rocks used in this study, because the price of aggregate depends strongly on the distance that it must be transported. For example, a beach sand may cost more inland than near the coast. However, white cement is typically twice as expensive as gray cement. If one's goal is to economically cast high-albedo concrete, it is interesting to compare the albedos of highly reflective gray-cement and white-cement mixes. In this experiment, the most-reflective gray-cement and white-cement concretes (both smooth) were formed with beach sand S4 $(\rho=0.45)$ and plagioclase rock R3 $(\rho=0.49)$. Their mature, unexposed albedos were 0.52 and 0.77 , respectively $\left(\delta_{w-g}=0.25\right)$. After exposure, the albedo of the high-reflectance gray-cement concrete ranged from 0.19 to 0.50 , and that of the high-reflectance white-cement concrete ranged from 0.58 to 0.79 . The white-cement concrete was always significantly more reflective than the gray-cement concrete $\left(\delta_{w-g}=0.18\right.$ to 0.39$)$.

The effects of weathering, soiling, and abrasion were measured separately. An approximate way to predict albedo after exposure to two or more of these processes is to assume that reflectance changes combine geometrically. For example, if the unexposed, weathered, and abraded albedos of a concrete are $\rho_{0}, \rho_{1}$, and $\rho_{2}$, respectively, we compute its albedo after both weathering and abrasion as $\rho_{0} \times r_{1} \times r_{2}$, where $r_{1} \equiv \rho_{1} / \rho_{0}$ and $r_{2} \equiv \rho_{2} / \rho_{0}$ (Figure 14). Geometric combination of the effects of abrasion, soiling, and weathering yields $r_{A B} \times r_{S O} \times r_{W E}$ values of $68 \%$ for the mostreflective gray-cement concrete, and $72 \%$ for the most-reflective white-cement concrete (Table 5). In other words, exposure to these three processes would reduce the albedo of each concrete to about $70 \%$ of its unexposed value, and the highest-albedo white-cement concrete would still be appreciably more reflective than the highest-albedo gray-cement concrete $\left(\delta_{w-g}=0.20\right)$.

Table 5. Combining exposure-induced albedo changes. Shown from left to right for each concrete are its unexposed albedo $\rho_{0}$; the measured ratios $r_{W E}, r_{S O}$, and $r_{A B}$ of exposed albedo to unexposed albedo after weathering, soiling, and abrasion, respectively; and predicted ratios for combined exposures.

\begin{tabular}{c|c|c|c|c|c|c|c|c} 
& $\rho_{0}$ & $r_{W E}$ & $r_{S O}$ & $r_{A B}$ & $r_{W E} \times r_{S O}$ & $r_{W E} \times r_{A B}$ & $r_{A B} \times r_{S O}$ & $r_{A B} \times r_{S O} \times r_{W E}$ \\
\hline $\begin{array}{c}\text { most-reflective } \\
\text { gray-cement concrete } \\
\text { C1:S4:R3 }\end{array}$ & 0.52 & $86 \%$ & $97 \%$ & $83 \%$ & $83 \%$ & $71 \%$ & $80 \%$ & $\mathbf{6 8 \%}$ \\
\hline $\begin{array}{c}\text { most-reflective } \\
\text { white-cement concrete } \\
\text { C2:S4:R3 }\end{array}$ & 0.77 & $103 \%$ & $88 \%$ & $79 \%$ & $90 \%$ & $82 \%$ & $70 \%$ & $\mathbf{7 2 \%}$
\end{tabular}




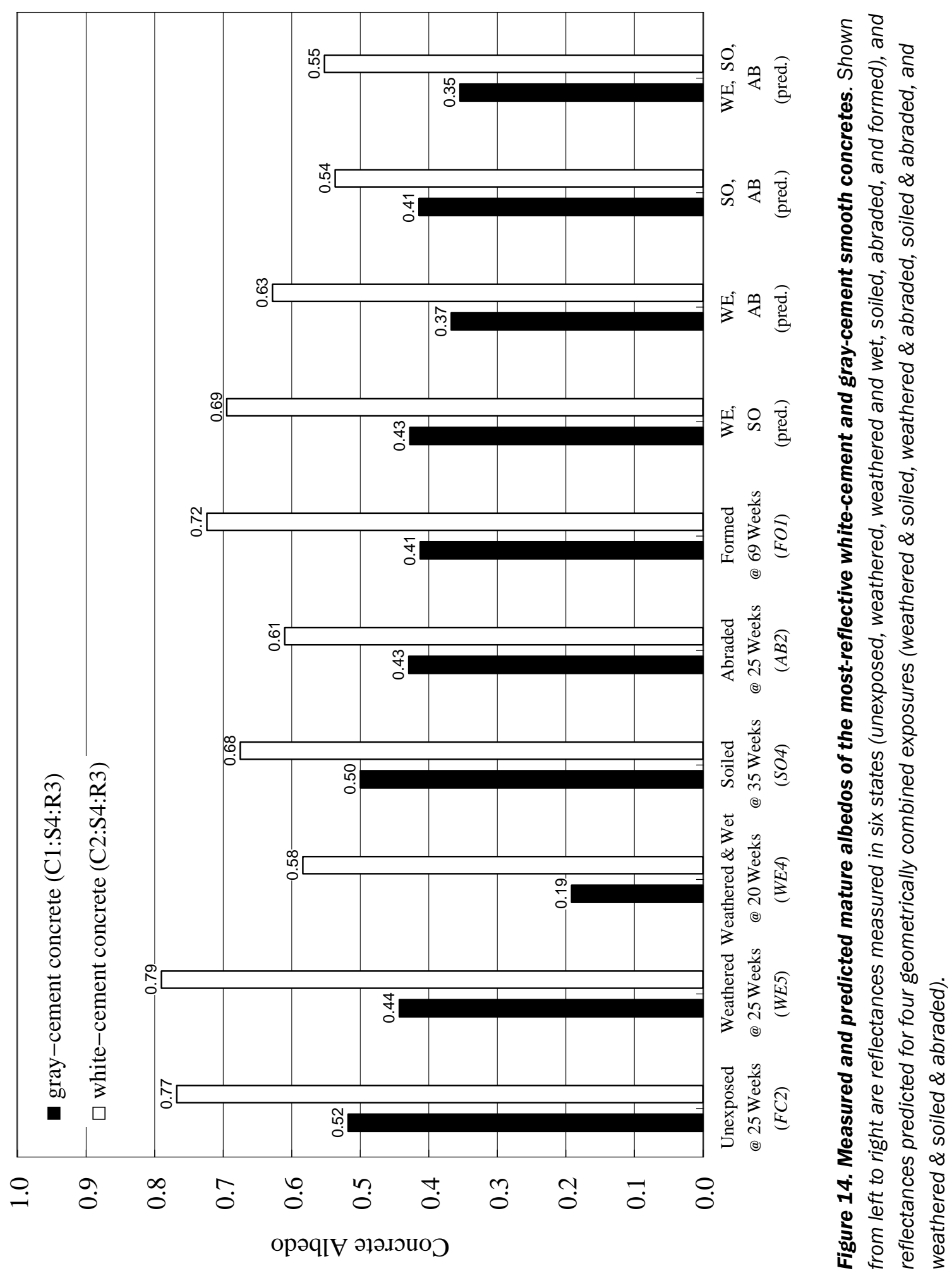


One way to increase the reflectance of gray-cement concretes is to promote efflorescence and carbonation through choice of aggregate. In this experiment, some concretes made with sands S1 (riverbed sand) and S4 (beach sand) were frosted. However, this whitening may not be permanent, because even insoluble films of calcium carbonate can gradually wash away after conversion to calcium bicarbonate, or be removed by abrasion. Patchily frosted surfaces can also be considered unattractive.

\subsection{Future Research}

This laboratory study examined small (and in some cases, improperly cast) concrete samples that were made from limited and arbitrarily chosen varieties of cement, sand, and rock. These were then subjected to improvised simulations of weathering, soiling, and abrasion. The next technical step toward developing practical high-reflectance concrete pavements might entail working with the concrete industry to (a) find locally available, structurally proven, high-albedo aggregates; (b) use promising concretes to pave segments of actual roads and parking lots; and (c) measure the real-world optical and mechanical performances of these pavements over time. This would help identify costeffective and mechanically sound varieties of concrete from which to fashion reflective pavements. Some concrete mixes could include fly ash and/or ground granulated blast furnace slag, which are coal-combustion byproducts that are used to replace or supplement cement and aggregate, respectively. Ideally, pavement consumers such as municipalities and developers would participate in future

research by specifying preferences for pavement properties (e.g., color and durability) and providing road and parking areas for pavement testing.

\section{Conclusions}

Concrete albedo grew as the cement hydration reaction progressed (mean increase 0.08), but stabilized within six weeks of casting. The mature albedos of the eight properly-made, "smooth" concrete mixes ranged from 0.41 to 0.77 (mean 0.59). Simulated weathering, soiling, and abrasion each reduced average concrete albedo (mean decreases 0.06, 0.05, and 0.19, respectively), though some samples became slightly more reflective through weathering or soiling. Simulated rain (wetting) strongly depressed the albedos of concretes (mean decrease 0.23) until their surfaces were dried. Exposure similarly affected the albedos of the improperly-made, "rough" concretes.

White-cement smooth concretes were on average significantly more reflective than gray-cement smooth concretes. The albedo of the most-reflective white-cement smooth concrete was 0.18 to 0.39 higher than that of the most-reflective gray-cement smooth concrete, depending on state of exposure. Smooth concrete albedo generally correlated with cement albedo and sand albedo, and, after abrasion, with rock albedo. Cement albedo had a disproportionately strong influence on the reflectance of smooth concrete. Efflorescence and surface carbonation whitened some gray-cement concretes. 


\section{References}

Akbari, H. and L.S. Rose. 2001. "Characterizing the fabric of the urban environment: a case study of Salt Lake City, Utah." Berkeley, CA; Lawrence Berkeley National Laboratory Report LBNL47851.

Akbari, H., L.S. Rose, and H. Taha. 1999. "Characterizing the fabric of the urban environment: a case study of Sacramento, California." Berkeley, CA; Lawrence Berkeley National Laboratory Report LBNL-44688.

ASTM. 1998. "Table G159-98: standard tables for references solar spectral irradiance at air mass 1.5: direct normal and hemispherical for a $37^{\circ}$ tilted surface." Annual Book of ASTM Standards, Vol. 14.04. Philadelphia, PA; American Society for Testing and Materials.

ASTM. 1999. “Practice E660-90 (1996): standard practice for accelerated polishing of aggregates or pavement surfaces using a small-wheel, circular track polishing machine." Annual Book of ASTM Standards, Vol. 04.03. Philadelphia, PA; American Society for Testing and Materials.

ASTM. 2001. "Practice G154-00ae1: standard practice for operating fluorescent light apparatus for UV exposure of nonmetallic materials." Annual Book of ASTM Standards, Vol. 14.04. Philadelphia, PA; American Society for Testing and Materials.

Bayer Corporation. 1997. "Efflorescence. A temporary problem." Pittsburgh, PA; Bayer Corporation, Industrial Chemicals Division.

Brunauer, S. and L.E. Copeland. 1964. "The chemistry of concrete." Scientific American, Vol. 210, No. 4 , pp. 80-92.

CIE/PIARC. 1977. Road Surfaces and Lighting. Paris; International Commission on Illumination (CIE) and Permanent International Association of Road Congresses (PIARC).

Fedor, G.R. and P.J. Brennan. 1996. "Correlation between natural weathering and fluorescent UV exposures: UVA-340 lamp test results." Durability Testing of Non-Metallic Materials, ASTM STP 1294, Robert J. Herling, Ed. Philadelphia; American Society for Testing and Materials.

Goode, C.D. 1991. “Weathering of concrete.” Concrete Construction (January).

Homburger, W.S. and J.H. Kell. 1984. Fundamentals of Traffic Engineering, $11^{\text {th }}$ Ed. Berkeley, CA; Institute of Transportation Studies, University of California.

Hooker, K.A. 1994. "Reducing efflorescence potential.” Masonry Construction (February). 
Hurd, M.K. 1988. "Aggregates bring lifetime color to concrete." Concrete Construction (June).

Hurd, M.K. 1993. "Tips for coloring concrete." Concrete Construction (May).

IES. 1983. American National Standard Practice for Roadway Lighting. New York; Illuminating Engineering Society of North America.

Jackett, M.J. and A.J. Fisher. 1974. "The light reflecting properties of asphaltic concrete road surfaces.” ARRB Proceedings, Vol. 7, Part 5, pp. 287-306.

Jung, W., A. Kazakov, and A.I. Titishov. 1984. "Road surface reflectance measurements in Ontario." Transportation Research Record, Issue 996, pp. 24-37.

Kenney, A.R. 1996. "Avoiding efflorescence in architectural precast concrete." Concrete Producer (July).

Kirk-Othmer. 1979. Encyclopedia of Chemical Technology, 3rd Ed. Vol. 5, pp. 163-192. New York; J. Wiley.

Lea, F.M. 1998. Chemistry of Cement and Concrete, 4th Ed. London; Arnold.

Lide, D.R. 1990. CRC Handbook of Chemistry and Physics, 71st Ed. Boca Raton, FL; CRC Press.

Mehta, P.K. and P.J.M. Monteiro. 1993. Concrete: Structure, Properties, and Materials, $2^{\text {nd }}$ Ed. Englewood Cliffs, NJ; Prentice Hall.

Nasvik, J. 2000. “Decorative concrete.” Concrete Construction (December).

Newman, H.B. 2000. “Everything efflorescent.” Masonry Construction (September).

Papadakis, V.G. and C.G. Vayenas. 1991. "Experimental investigation and mathematical modeling of the concrete carbonation problem.” Chemical Engineering Science, Vol. 46, No. 5/6, pp. 1333-1338.

Rosenfeld, A.H., H. Akbari, J.J. Romm, and M. Pomerantz. 1998. "Cool communities: strategies for heat island mitigation and smog reduction." Energy \& Buildings, Vol. 28, pp. 51-62.

Schierhorn, C. 1996. “Ensuring mortar color consistency.” Masonry Construction (January).

Twomey, S.A., C.F. Bohren, and J.L. Mergenthaler. 1986. "Reflectance and albedo differences between wet and dry surfaces." Applied Optics, Vol. 25, No. 3, pp. 431-437. 



\section{Appendices}

\section{A Effects of Wetting and Drying on Rate Of Concrete Albedo Growth}

The rate of concrete albedo growth varied between sample sets. For example, there was a noticeable root-mean-square difference between the albedos of unexposed concrete sets $F C$ and $S O$ at week six (FC1 vs. S01: $\chi_{\mathrm{s}}=0.10 ; \chi_{\mathrm{a}}=0.07$ ) (Figure A-1). These reflectance differences may have resulted from variations in the degree to which concretes were dried with a hot-air gun prior to albedo measurement (see Section 2.1). That is, varying amounts of water may have been driven out of the concretes when their surfaces were dried. Such changes to water content would affect the cement hydration process.

Absorbed water temporarily depressed the albedos of curing concretes even after their surfaces were dried. For example, set SC (unexposed) was wetted and dried at five weeks to simulate rain. Its mean albedo at five weeks was appreciably higher dry than wet (SC2 vs. SC1: $\delta_{s}=0.22, \chi_{s}=0.23 ; \delta_{a}=0.13$, $\chi_{\mathrm{a}}=0.15$ ) (Figure A-2), but still lower than that of unexposed, never-wetted set FC at six weeks (SC2 vs. FC1: $\delta_{s}=-0.05, \chi_{s}=0.08 ; \delta_{a}=-0.08, \chi_{a}=0.11$ ) (Figure A-3). This albedo-depression effect diminished over time. By week 25, the mean albedo difference between never-wetted set $F C$ and oncewetted set SC was quite small (FC2 vs. SC3: $\delta_{s}=0.02, \chi_{s}=0.04 ; \delta_{a}=0.02, \chi_{a}=0.04$ ).

Wetting and drying the surfaces of older concretes had little long-term effect on their albedos. For example, the reflectances of the weathered surfaces were measured dry at 18 weeks (WE3), wet at 20 weeks (WE4), and dry again at 25 weeks (WE5). Their mean dry albedo at 25 weeks was only slightly higher than at 18 weeks (WE5 vs. WE3: $\delta_{s}=0.01, \chi_{s}=0.02 ; \delta_{a}=0.01, \chi_{a}=0.03$ ) (Figure A-4). 


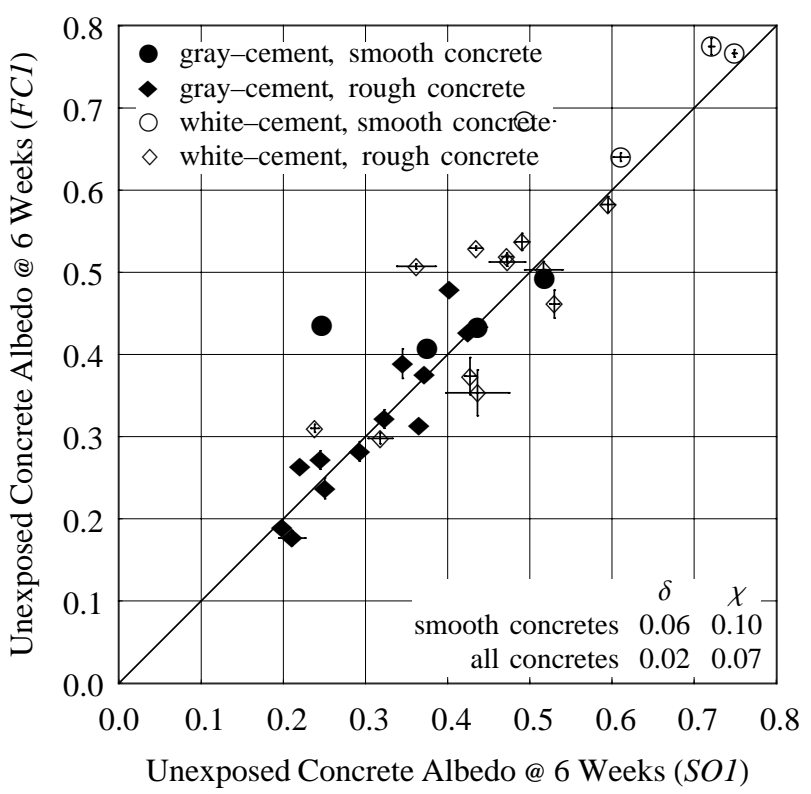

Figure A-1. Set-to-set differences in albedos of unexposed concretes. The albedos of some unexposed, unwetted concretes differed noticeably from set to set at week six, possibly due to wetnessrelated variations in rates of curing.

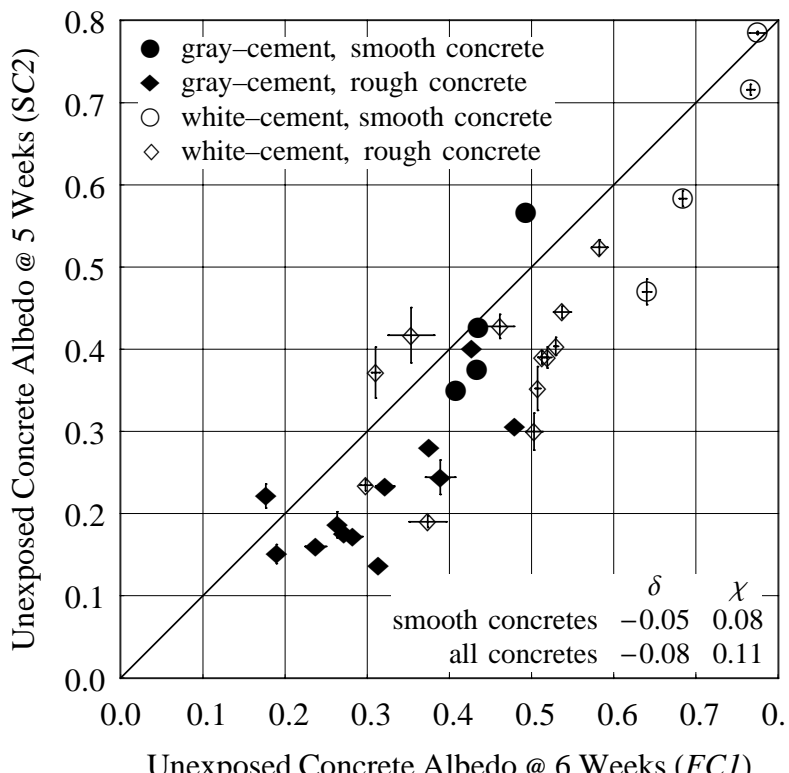

Figure A-3. Effect of wetting and drying on albedo growth in immature concretes. The albedos at week five of many wetted-and-dried, unexposed concretes were appreciably lower than those at week six of their never-wetted, unexposed counterparts.

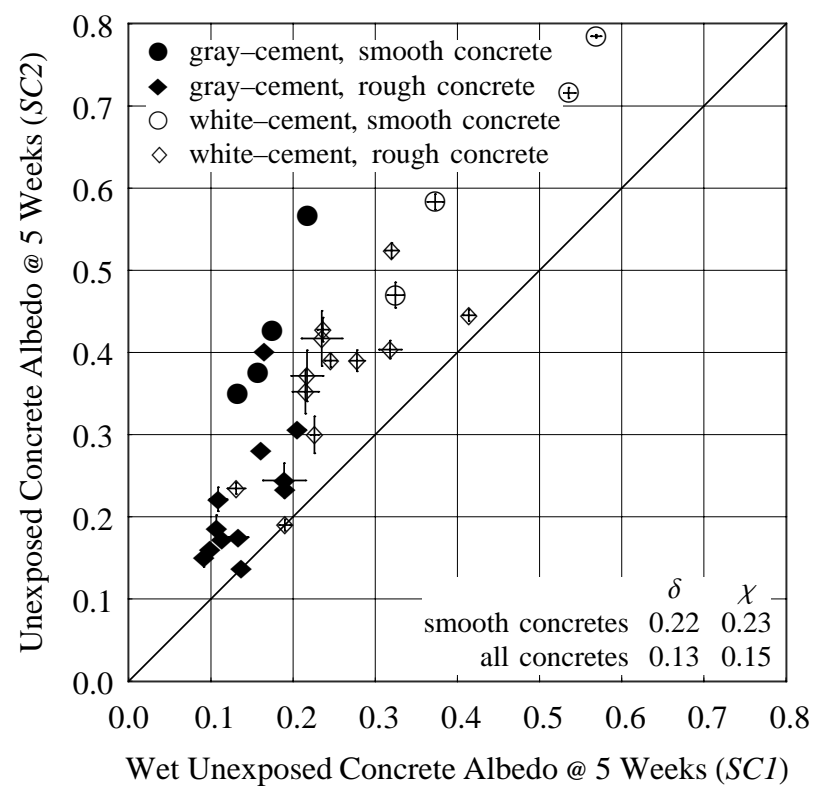

Figure A-2. Immediate effect of drying on albedo of wet concrete. Drying significantly increased the albedos of many wetted, unexposed concretes at week five.

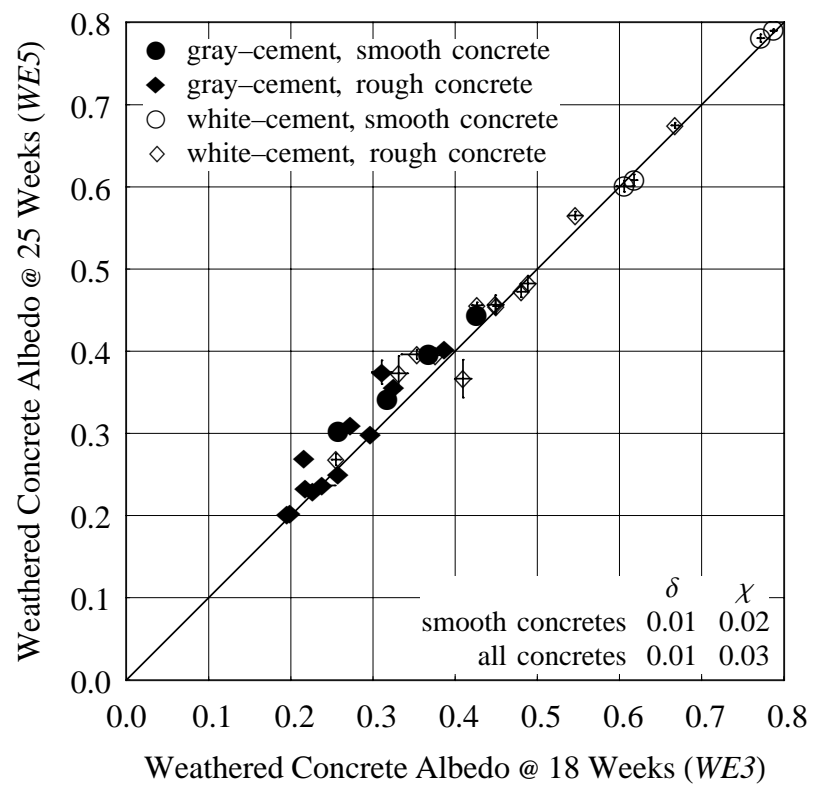

Figure A-4. Effect of wetting and drying on albedo growth in mature concretes. The albedos of mature weathered concretes changed little from weeks 18 to 25, despite wetting and drying at week 20. 


\section{B Albedos of Mature Concretes}

This appendix details the "mature" reflectances of the 32 mixes of concrete. These albedos were measured after at least 20 weeks of curing, and are presumed to have stabilized because the reflectance of unexposed concrete changed very slowly after six weeks of curing (see Section 3.1).

Albedo Distributions. The albedos of weathered, weathered and wetted, soiled, abraded, and formed surfaces of each variety of concrete are shown in Figure B-1 through Figure B-5.

Concrete Albedo Vs. Composition. The variations of the albedos of formed, weathered, soiled, and abraded concretes with albedos of cement, sand, and rock are shown in Figure B-6 through Figure B-8. 


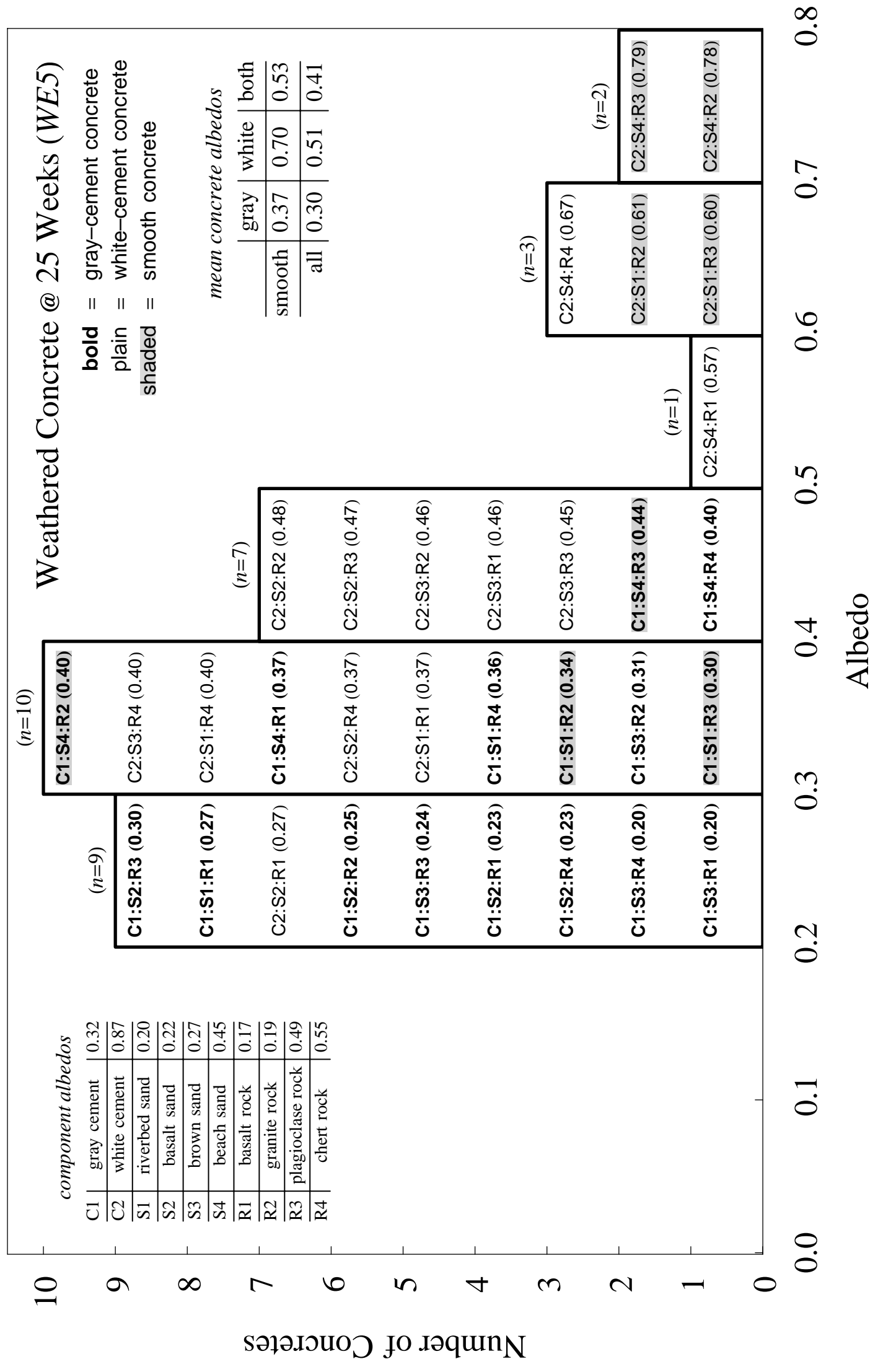

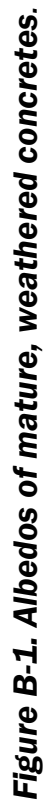




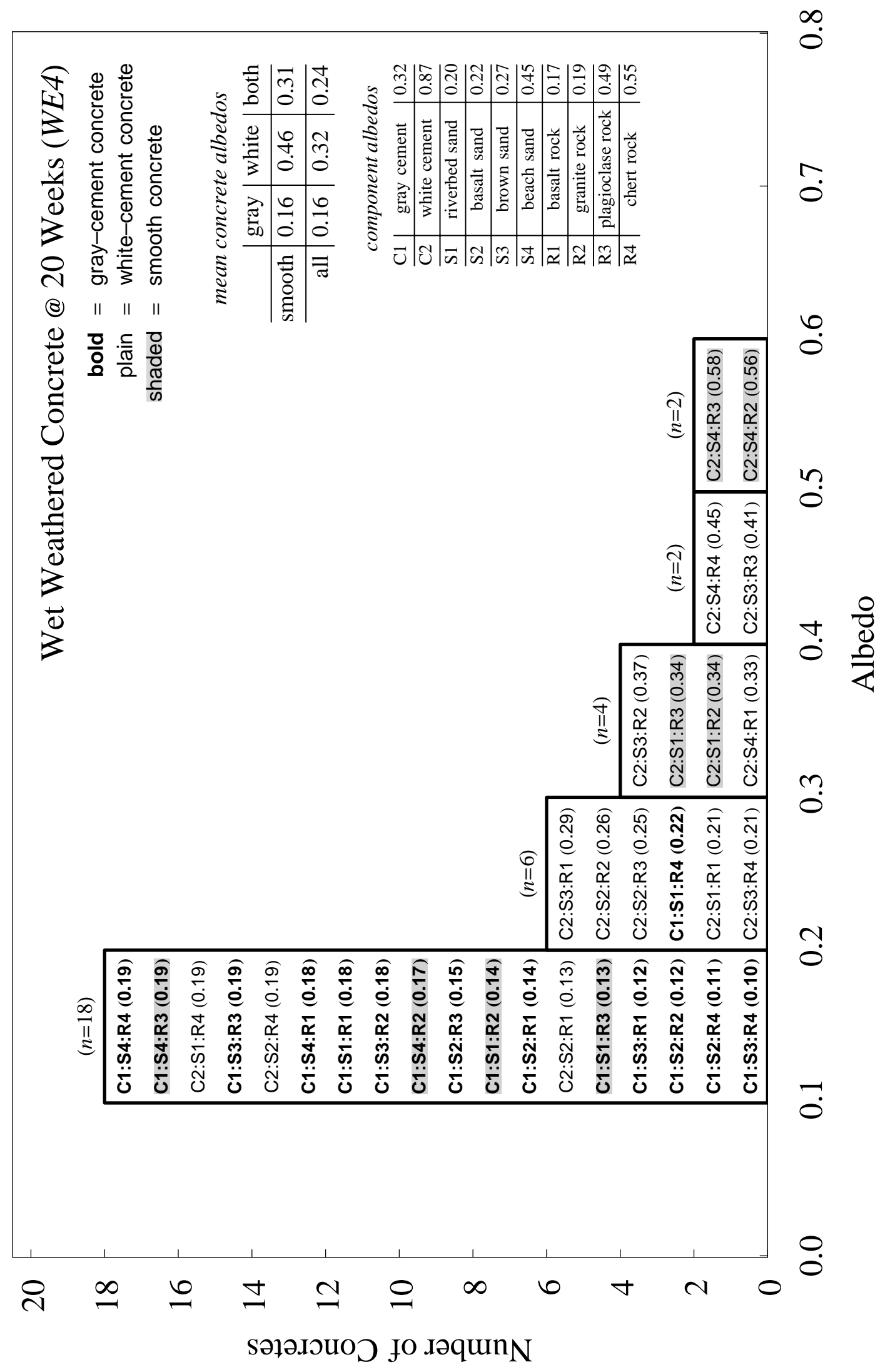

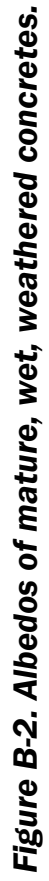




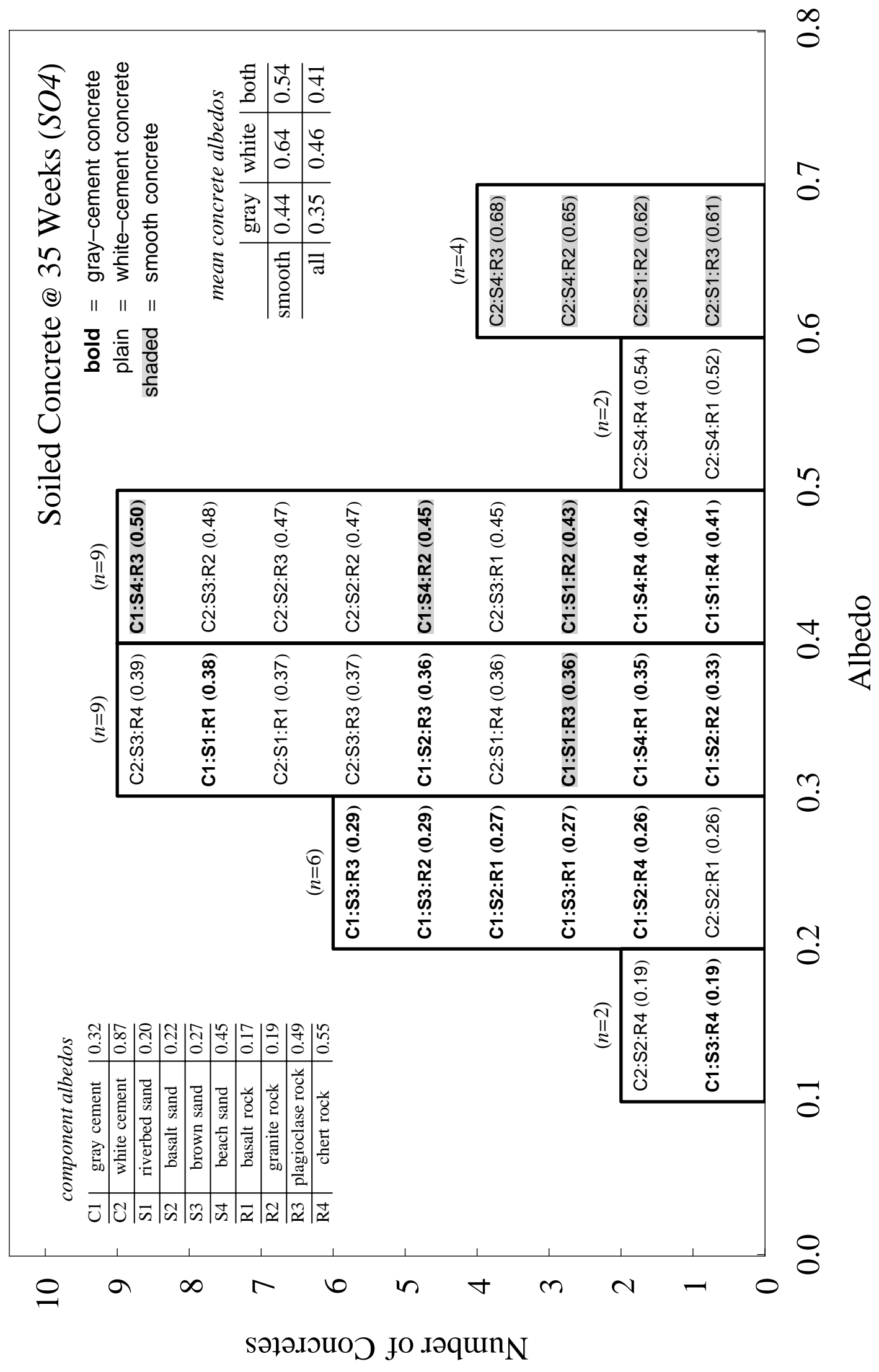

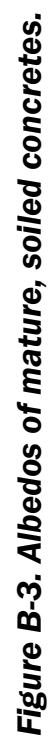




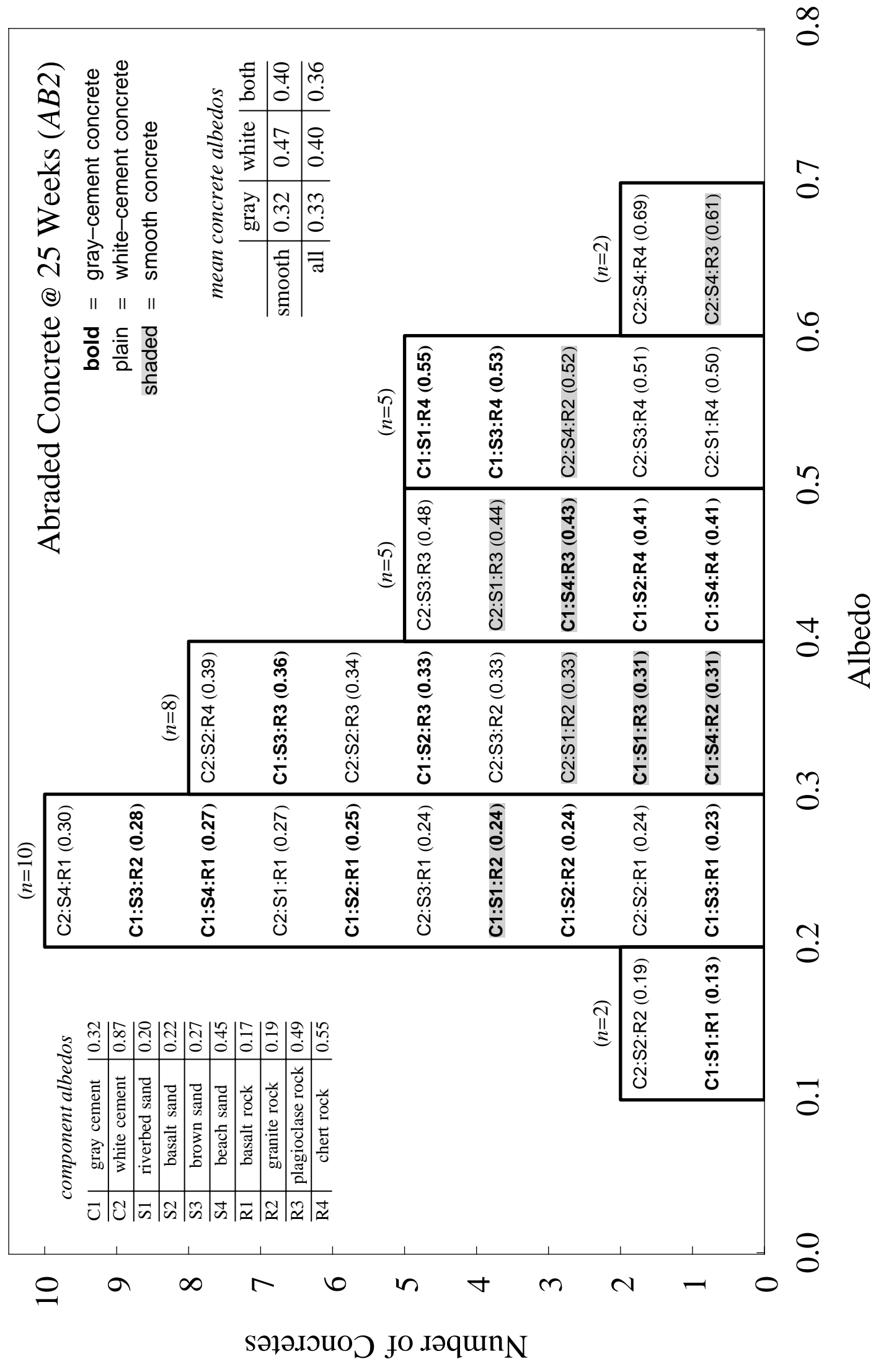

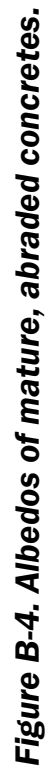




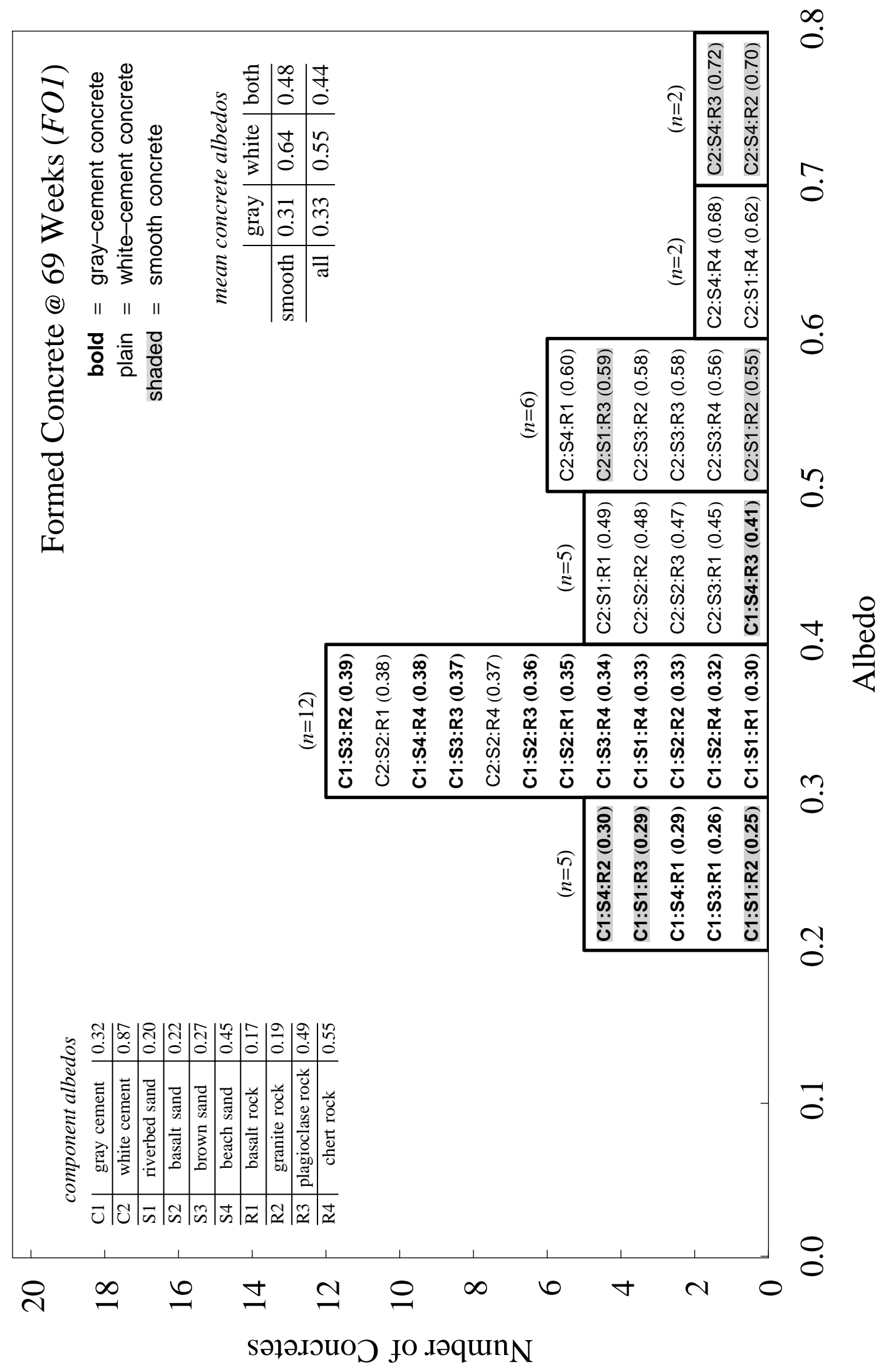

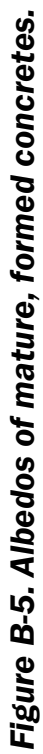


$\mathrm{C} 1$

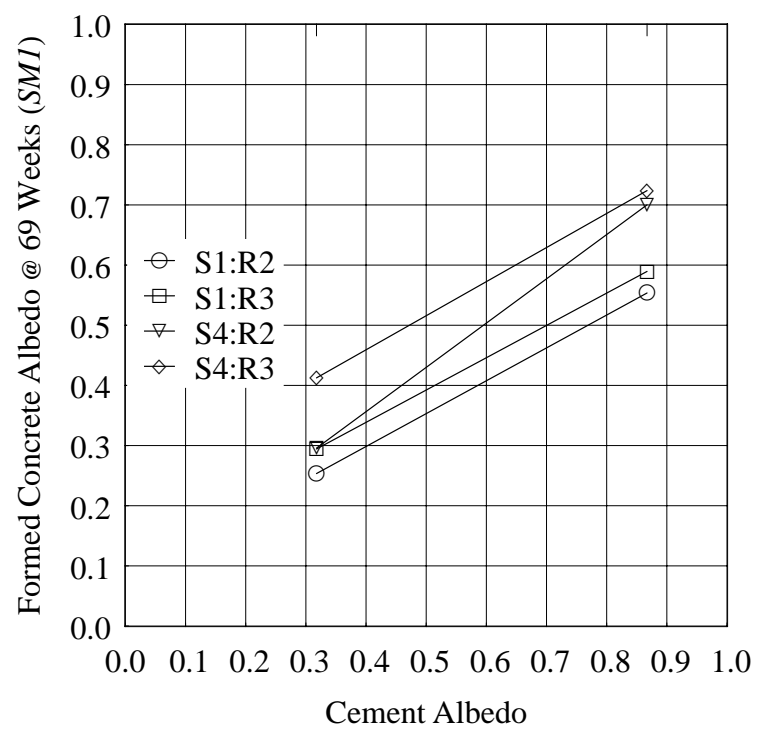

(a)

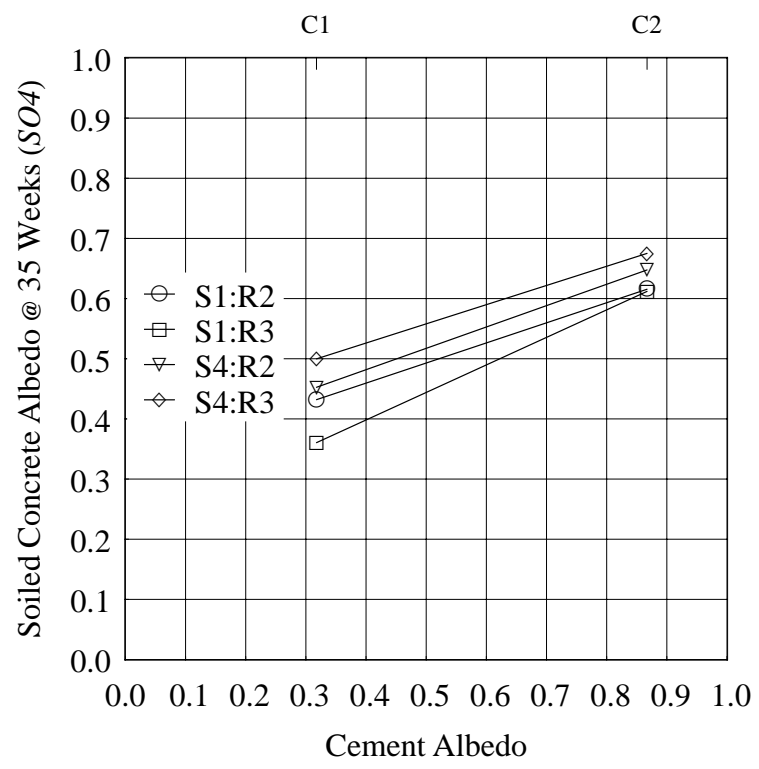

(c)

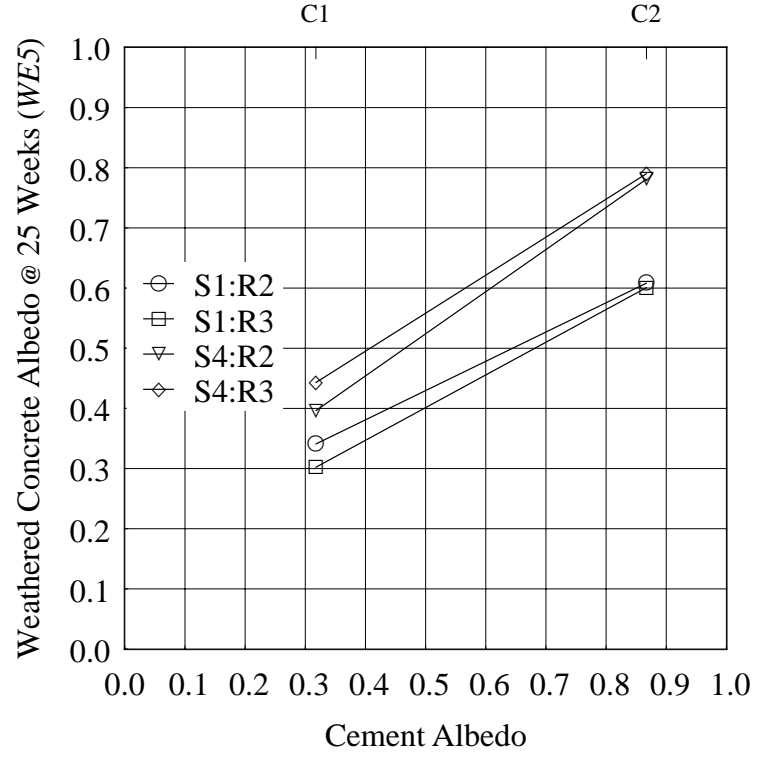

(b)

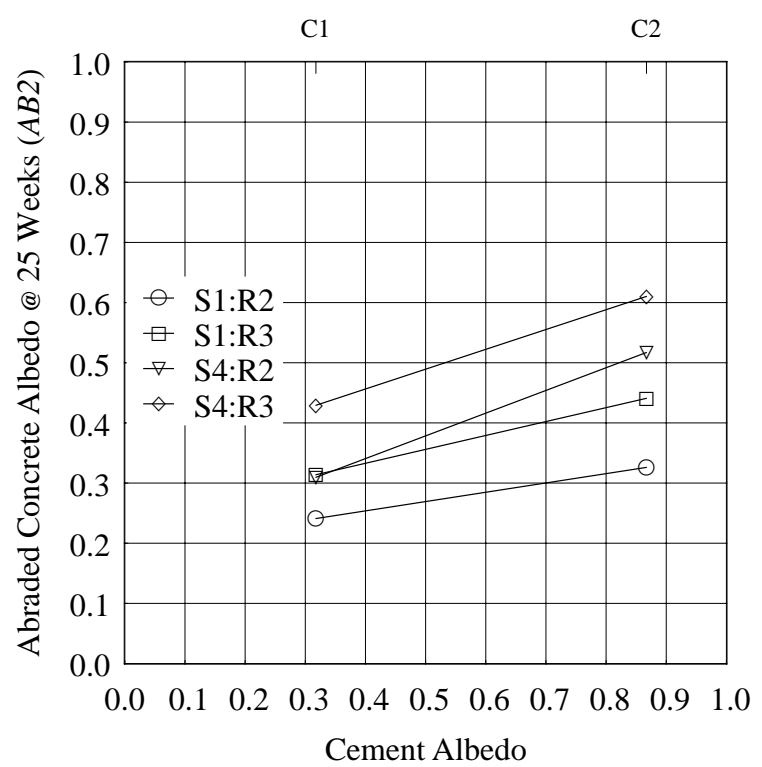

(d)

Figure B-6. Mature, smooth concrete albedo vs. cement albedo. Mature albedos of (a) formed, (b) weathered, (c) soiled, and (d) abraded smooth concretes correlated with cement albedo. Lines connecting data points should not be used for interpolation. 


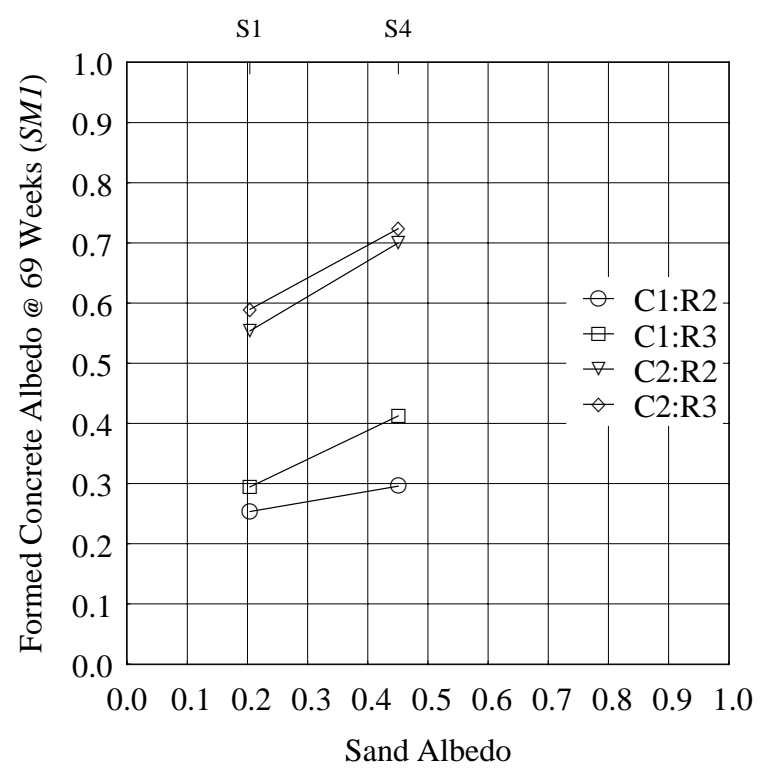

(a)

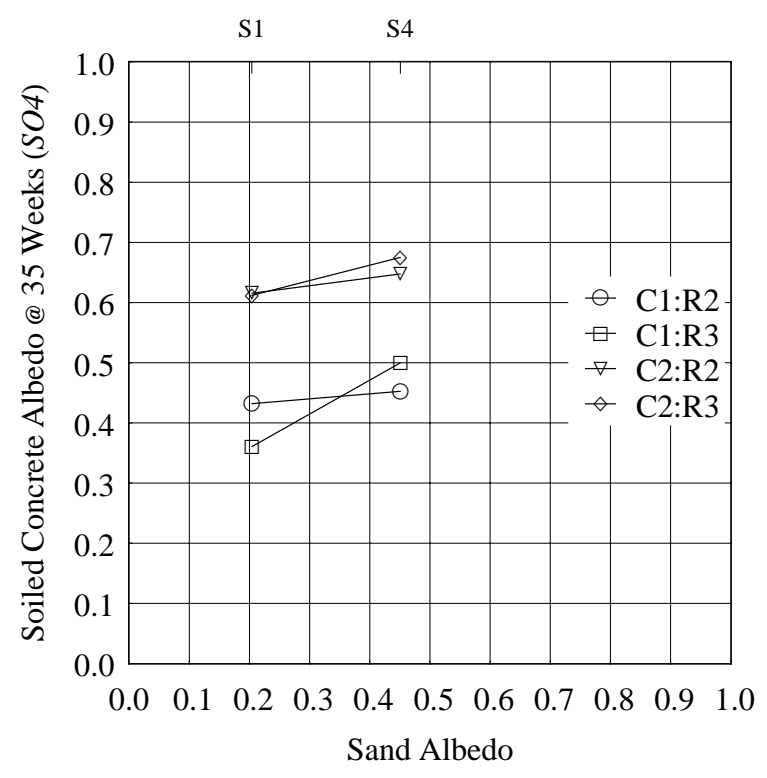

(c)

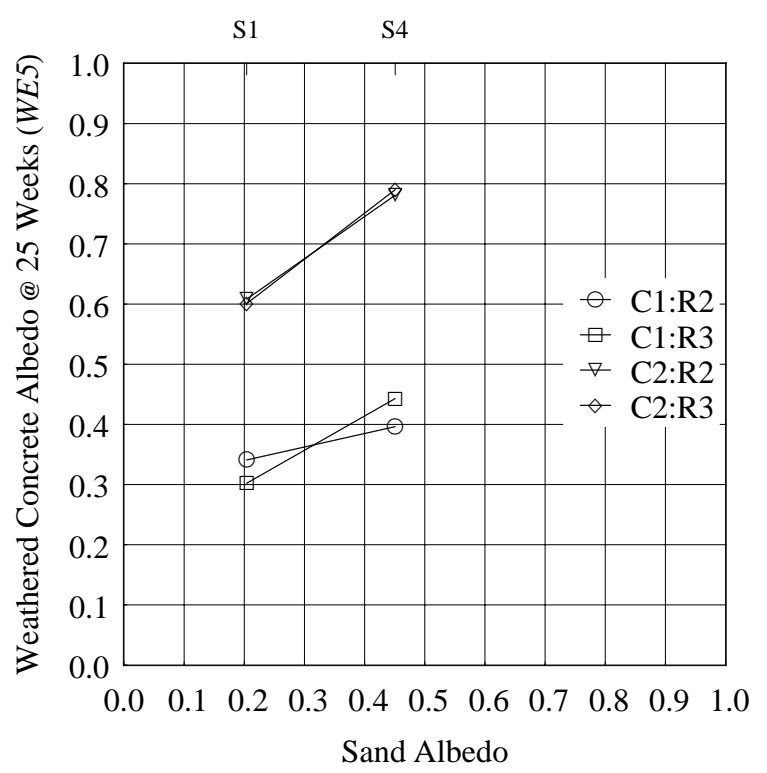

(b)

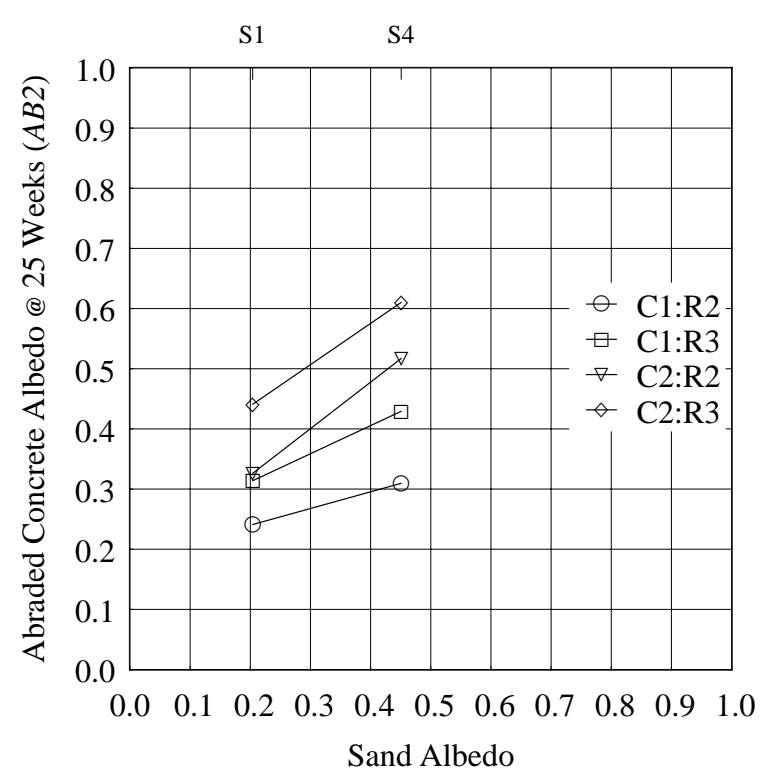

(d)

Figure B-7. Mature, smooth concrete albedo vs. sand albedo. Mature albedos of (a) formed, (b) weathered, (c) soiled, and (d) abraded smooth concretes correlated with sand albedo. Lines connecting data points should not be used for interpolation. 


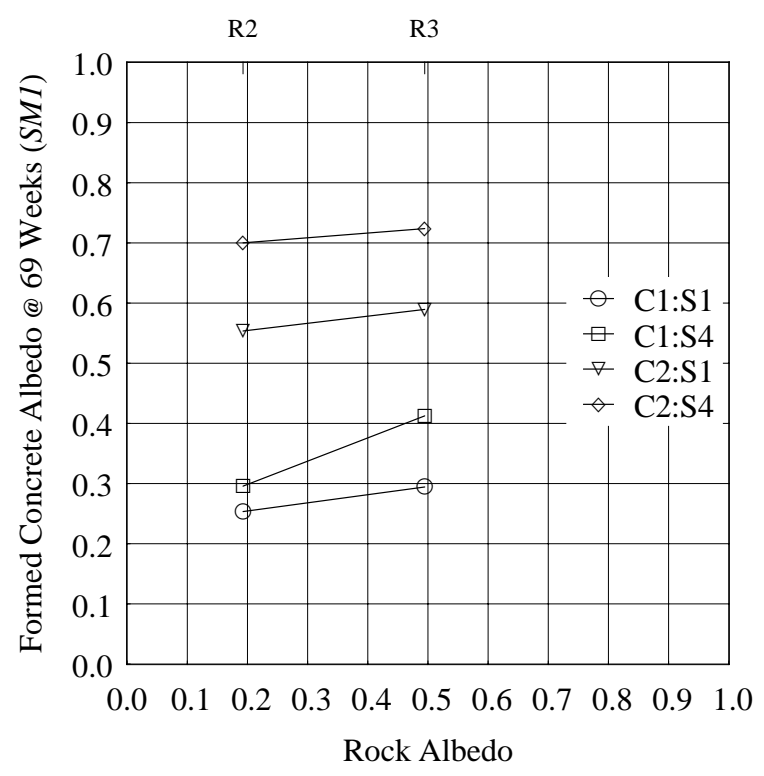

(a)

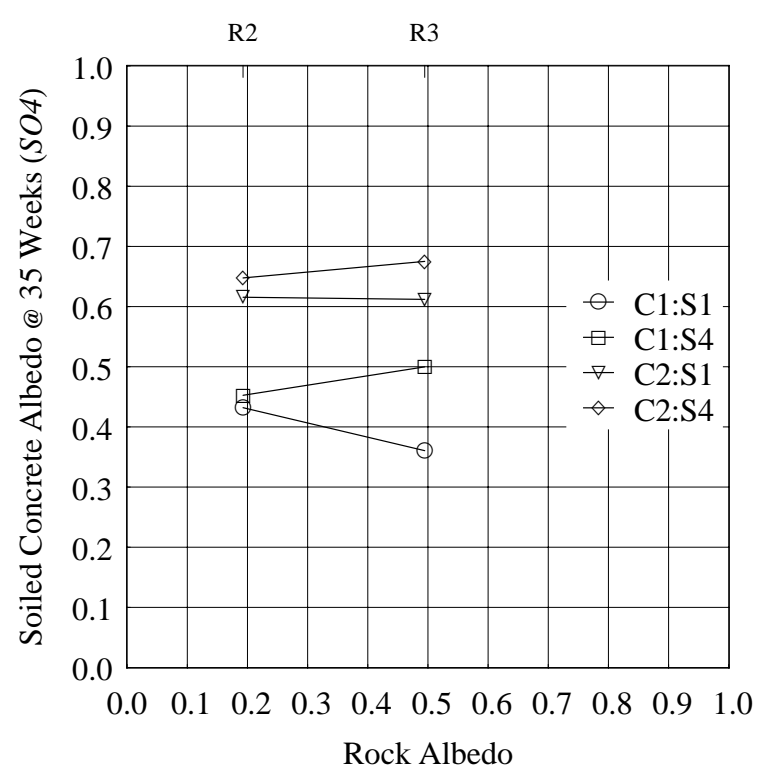

(c)

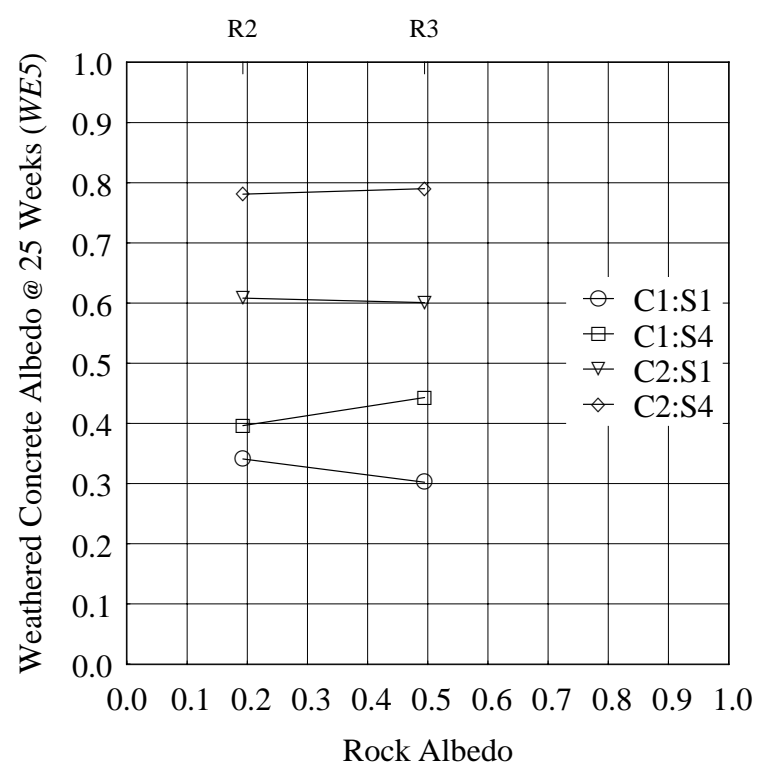

(b)

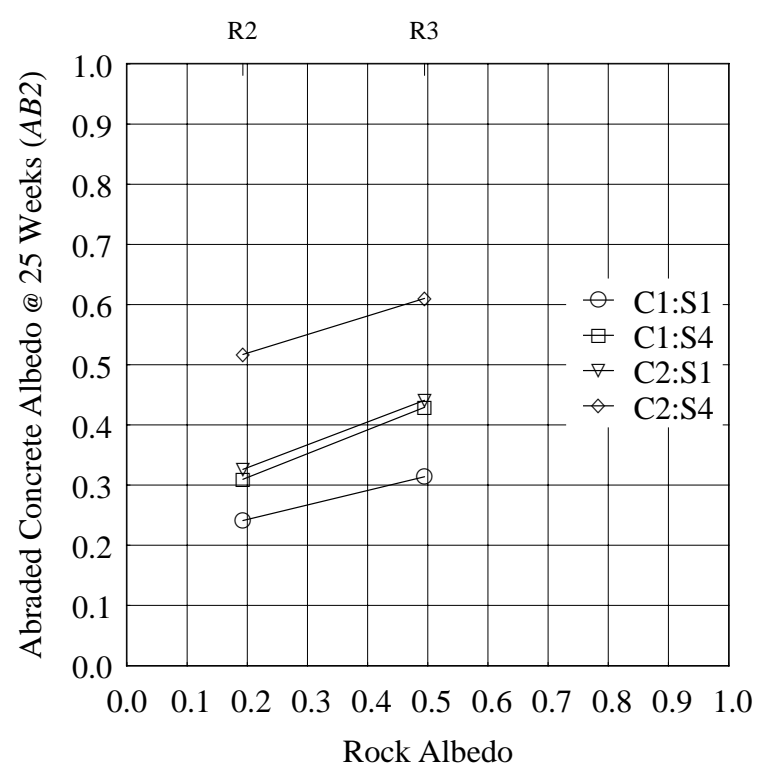

(d)

Figure B-8. Mature, smooth concrete albedo vs. rock albedo. Mature albedos of (a) formed, (b) weathered, and (c) soiled smooth concretes did not strongly correlate with rock albedo, but that of (d) abraded smooth concrete did well correlate with rock albedo. Lines connecting data points should not be used for interpolation. 